\title{
Masonry Infill RC Frames with Openings: Review of In-plane Lateral Load Behaviour and Modeling Approaches
}

\author{
Sachin Surendran and Hemant B. Kaushik*
}

Department of Civil Engineering, Indian Institute of Technology Guwahati, Guwahati 781039, India

\begin{abstract}
Un-reinforced masonry walls are commonly used as infills in reinforced concrete (RC) buildings. These buildings have high in-plane stiffness and strength, and therefore, the lateral load behaviour of such RC frames is different than that of the frames without infill walls. Openings in walls significantly reduce the lateral strength and stiffness of RC frames, and alter their failure modes. Past researchers have tried to find out experimentally and analytically the influence of several parameters, like opening size and location, aspect ratio of openings, connection between frame and infill wall, ductile detailing in frame members, material properties, failure modes, etc. on behavior of masonry infill RC frames. Accordingly, several analytical models have been proposed in the literature and seismic codes of some countries to model the stiffness and strength properties of infill walls. Most of the past studies and seismic codes recommend modeling the infills as equivalent diagonal struts, and cross-sectional area of the struts are reduced appropriately to account for openings in the walls. Analytical methods have also been proposed to estimate the possible mode of failure and lateral load carrying capacity of infill frames with and without openings. The current article is intended to review and compare past relevant studies and seismic codes of different countries on in-plane lateral load behaviour and modeling approaches for masonry infill $\mathrm{RC}$ frames with openings. The comparative study may help designers and code developers in selecting and recommending suitable analytical models for estimating strength, stiffness, failure modes, and other properties of infill RC frames with openings.
\end{abstract}

Keywords: Lateral load, masonry infills, openings, stiffness, strength.

\section{INTRODUCTION}

Reinforced concrete (RC) frames infilled with unreinforced masonry walls are quite commonly constructed all across the globe since many decades. The practice of using infill walls has been under scrutiny as it has both positive and negative effects on the behavior of structure under lateral load [1-3]. Though infill walls do not affect the behavior of frames under gravity loading, lateral stiffness and strength of frames increase significantly under the action of lateral loads. Therefore, unsymmetrical distribution of mass owing to randomly placed infills can actually change the structural response to earthquake load. Infills are generally provided for partitioning, and the position of infills can change throughout the life span of the building due to change in the functional requirements thus changing the lateral load behavior, which is difficult to predict. In addition, openings in infill walls (for doors and windows) affect the behavior of frames, and the effect of openings on the lateral stiffness and strength of such frames is a research area of much significance. Large number of experimental and analytical studies has been undertaken in the past to investigate the behavior of such frames under lateral loads. The failure of infill with openings under the action of lateral loads is mainly due to the concentration of stresses near the openings. From the past studies it was concluded that the stresses concentrate

*Address correspondence to this author at the Department of Civil Engineering, Indian Institute of Technology Guwahati, Guwahati, 781039, India; Tel: +91 361 2582427; Fax: +91 361258 2440;

E-mail: hemantbk@iitg.ac.in near the corners of the openings resulting in the failure. Providing stiffeners around the opening is a common practice to avoid large stress concentration near the openings. Infilled panels with openings are best viewed as assemblies of subcomponents of the appropriate material. The frame response is altered by the interaction of these subcomponents with the surrounding frame. Major types of interaction that occur are strong columns and strong piers inducing shear failure in the beams, reduction of ductility by causing short-column effects as a result of strong spandrel components and tension yielding or bar splice failures in the column induced by infills. The position, size and geometry of the openings were varied to study how these parameters affect the response of frames to lateral load. It has been observed that even infills with openings provide significant lateral stiffness and strength to frames. In some studies, the frames with opening area more than $50 \%$ of the total infill area behaved more like a bare frame. Formation of equivalent diagonal strutseven in infills with openings has been observed experimentally. Therefore, most popular method for analytical modeling of masonry infills is based on the concept of replacing the infill with equivalent diagonal struts. Various other methods were also used based on finite element techniques, discrete element method (DEM) and discontinuous deformation analysis (DDA).

The current article reviews and compares the past analytical and experimental studies and seismic codes of different countries on masonry infill RC and steel frames with a special emphasis on infill walls with openings. It is extremely important to understand the effects of openings in 

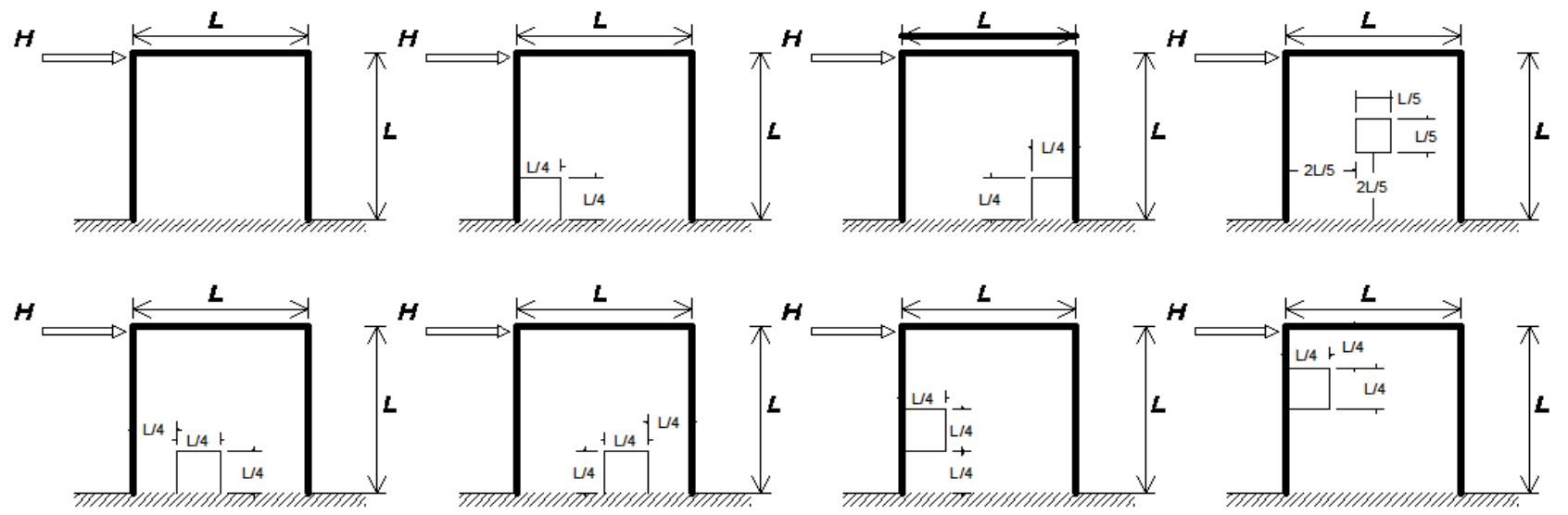

Fig. (1). Different size,shape and position of openings [4].

masonry infill walls on lateral stiffness, strength, failure modes, modeling approaches of RC frames for their effective and realistic design.

\section{Experimental Assessment of Lateral Strength, Stiffness, and Failure Modes}

Mallick and Garg [4] studied the effects of possible positions of openings on the lateral stiffness of infilled frames. It was one among the first extensive study on infilled frames with openings in which authors tested frames with and without shear connectors. The results of the experimental study were compared with the results of the theoretical prediction from finite element approach. According to authors, increasedstiffness of infill walls is due to: the presence of interaction forces, causing a bi-stress condition (shear and normal stress), and increase in the in-plane moment of inertia of the composite frame. Primary objectives of the study included: (1) finding the effect of different opening positions on the lateral stiffness and ultimate load of infilled frames, (2) studying the relative merits and demerits of different opening positions and recommending the suitable opening positions for doors and windows, (3) examining the behaviour of two types of frames, those with and without shear connectors, under identical loading conditions, and (4) comparing the experimental results with theoretical solutions using a finite element method to verify validity of the assumptions made in the study. Authors used square openings in the study. Except for central openings, the size of the opening used was one-fourth of the dimension of the infill panel. For central openings an opening size of one-fifth of the panel size was used and different opening positions tried are shown in Fig. (1). Masonry infills were provided in square mild steel frames and loading was applied using a vertical jack fixed on a loading frame 20 ton proving ring (Fig. (2)). The lateral deflections were measured by a mechanical dial gauge. It was concluded that if an opening is provided at either end of the loaded diagonal in an infilled frame without connectors, its lateral strength is reduced by about $75 \%$ and its stiffness by $55-90 \%$ as compared to that of an infilled frame without opening.

For infilled frames with shear connectors Fig. (2), the presence of an opening on either end of the loaded diagonal reduced its stiffness by $60-70 \%$ as compared to that of a similar infilled frame with a solid panel (without opening).
For both these types of frames the loss of strength and stiffness due to a centrally loaded square opening having side dimensions one-fifth those of the panel was about $25-50 \%$ as compared to that of similar frames without openings. It was obvious from the above findings that the openings at either end of the loaded diagonal are structurally unsuitable, and therefore, authors recommended that the door opening can best be located in the centre of the lower half of the panel and the window opening in the mid-height of the left or right half of the panel near to the vertical edge of the panel as far as possible.
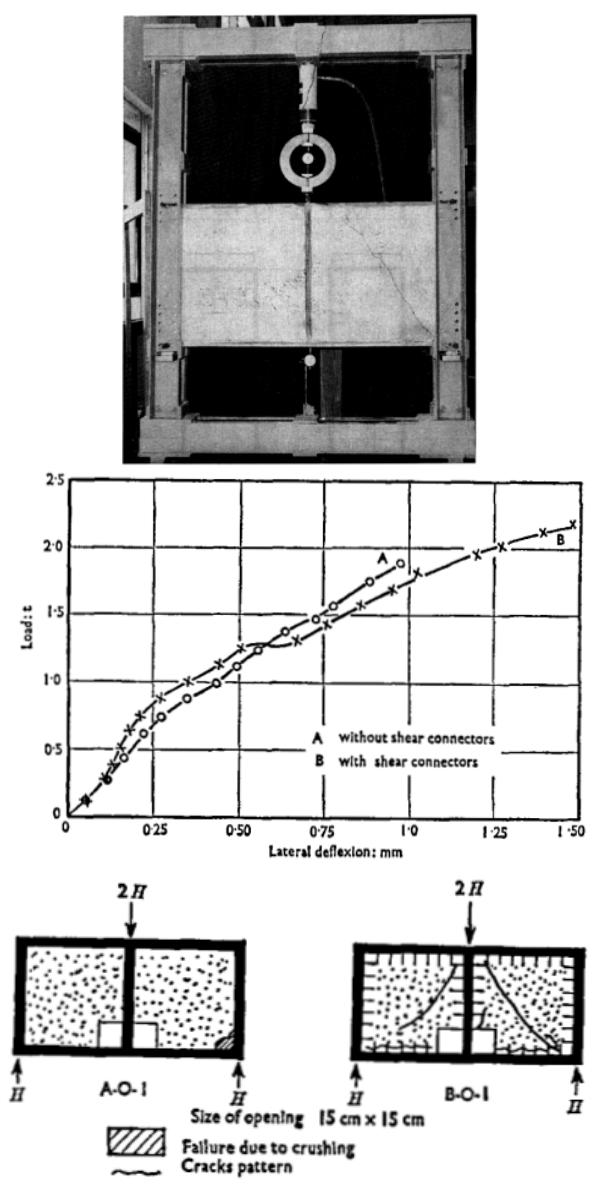

Fig. (2). Loading frame, load-deflection curves of two specimens together with the failure pattern of square infilled frames with and without shear connectors [4]. 
Table 1. Modes of Failure, Reduction in Strength and Stiffness [5].

\begin{tabular}{|c|c|c|c|c|}
\hline Model & $\frac{\text { width of opening }}{\text { width of infill }}$ & Mode of failure & Reduction in stiffness $(\%)$ & Reduction in strength $(\%)$ \\
\hline AS1 & 0 & Shear failure at base & 0 & 0 \\
\hline AS2 & 0.20 & Shear failure at top lintel beam & 7 & 43 \\
\hline AS4 & 0.30 & Shear failure at $3^{\text {rd }}$ story lintel beam & 11 & 47 \\
\hline $\mathrm{AO} 1$ & 0 & Diagonal compression failure at $3^{\text {rd }}$ story & 0 & 0 \\
\hline $\mathrm{AO} 2$ & 0.20 & Bending failure at top lintel beam & 68 & 62 \\
\hline $\mathrm{AO} 4$ & 0.30 & Bending failure at top lintel beam & 77 & 51 \\
\hline $\mathrm{CS} 1$ & 0 & Shear failure at top panel & 0 & 0 \\
\hline $\mathrm{CS} 2$ & 0.20 & Shear failure at top lintel beam & 38 & 53 \\
\hline CS4 & 0.30 & Shear failure at $3^{\text {rd }}$ story lintel beam & 47 & 59 \\
\hline $\mathrm{CO} 1$ & 0 & Diagonal compression failure at $3^{\text {rd }}$ story & 0 & 0 \\
\hline $\mathrm{CO} 2$ & 0.20 & Bending failure at top lintel beam & 60 & 38 \\
\hline $\mathrm{CO} 4$ & 0.30 & Bending failure at top lintel beam & 69 & 32 \\
\hline
\end{tabular}

Four story models of steel frames with micro concrete infills were tested by Liauw [5]. Micro concrete used had maximum aggregate size of $5 \mathrm{~mm}$, and $22 \times 22 \mathrm{~mm}$ square bars were welded to form the frames. Models were divided into two groups: with shear connectors "S" and without any shear connectors "O". Walls were provided with two layers of No.17 SWG wire mesh representing light reinforcement of $0.56 \%$ of concrete cross-section. The modes of failure together with the reduction in strengths and stiffness of the infilled frames are given in Table $\mathbf{1}$.

The stiffness was obtained from the initial tangent modulus of the slopes of the load-deflection curves. The openings in the infills generally induced early cracks at relatively early stages of the loading. Cracks first occurred at the top corners of the openings in all series of models. Models with openings in infills failed by bending in the lintel beam when there were no connectors, and, when there were connectors, they failed by shear in lintel beams. In the case where the connectors were used, the cracks propagated towards the steel frames until the cracked line met the connectors. When the openings were wide, cracks developed lower down in the lintel beams and resulted in shear failure of the beam. In case where connectors were provided, the failure started in the top lintel beam by bending compression. The provision of shear connectors increased the stiffness of infilled frames, even when there are openings in the infills.

Kakaletsis and Karayannis [6] tested eight singlestory singlebay $1 / 3$ scale specimens of RC frames with masonry infills including one bare frame and one frame with solid infill, three specimens with window openings at various locations and three specimens with door openings. The frame represented typical ductile concrete construction and in particular structures built in accordance to currently used codes and standards in Greece. Masonry infills had a height/length ratio $(h / l)$ of $1 / 1.5$, and were constructed using half-scale bricks (Fig. (3a)). The lateral load was applied using a hydraulic actuator and the vertical loads were exerted by hydraulic jacks through four strands at the top of each column and were kept constant during each test. The level of this axial compressive load per column was set equal to $50 \mathrm{kN}$ ( $10 \%$ of the ultimate load). It was observed that the frames with openings had a lateral load resistance of about 1.38 to 1.64 times that of the corresponding bare frame. The decrease in the load resistance was more when the location of the opening was towards the centre of the span on the diagonal. The presence of infill (with openings) improved the initial stiffness of all the frames by about 1.52 to 2.14 times compared to that of the bare frame. As in case of lateral load resistance, the decrease in the stiffness was also higher when opening was moved towards the center. The total energy dissipation capacity of the frames was found to be 1.02 to 1.49 times the capacity of bare frames. Reduction in stiffness was significant after the maximum resistance as evident from Figs. (3b and 3c), and loss of stiffness tends asymptotically towards the bare frame at higher drifts. The loss of stiffness was more in the case of frames with door openings than the ones with window openings when the openings were located at the centre. It was concluded that presence of infills, even with openings, improves stiffness, ductility, energy dissipation and lateral load resistance of frames.

Seven one third scale, single story, single bay frame specimens were tested under reversed cyclic, quasi-static, lateral loading up to a drift level of $40 \%$ and the parameters investigated were opening location and the infill compressive strength [7]. Specimens with openings at various locations were tested with weak infill and the frame with strong infill had opening at the centre. Elevation, corresponding cross-sections of the members and the design details are shown in Fig. (4). 


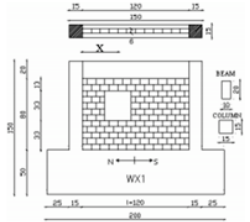

(a)

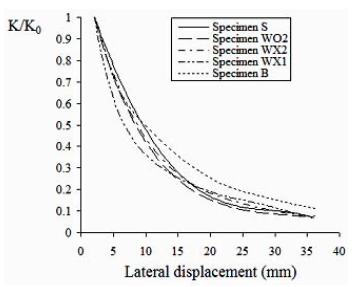

(b)

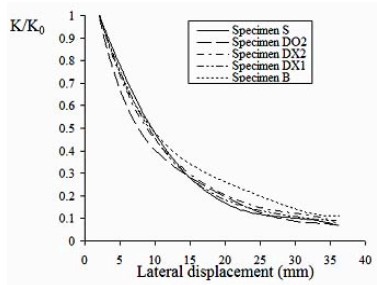

(c)

Fig. (3). (a) Test setup, (b) stiffness reduction in the frames for various window locations, and (c) stiffness reduction in the frames for various door locations [6].

Lateral load was applied using hydraulic actuator and vertical load applied at the top of the columns was equal to $50 \mathrm{kN}$.Hysteretic response of one frame with eccentric placement of infill wall along with details of crack formation is shown in Fig. (5). It was noted that the lateral strength of the frame with weak masonry infill was in some cases higher than the corresponding ones of the strong masonry infill and was attributed to the larger units of the weak masonry infill. It was concluded that the location of the opening towards the centre of the span, on the diagonal, resulted in further decrease of resistance, residual resistance, stiffness, ultimate limit state, ductility factor, normalized cumulative energy dissipation and larger amounts of loss of strength and energy due to loading.

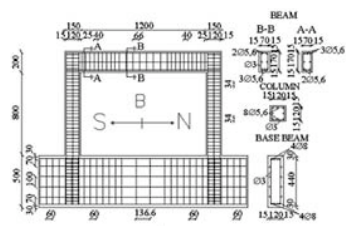

(a)

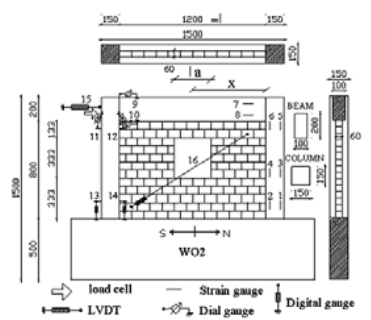

(b)

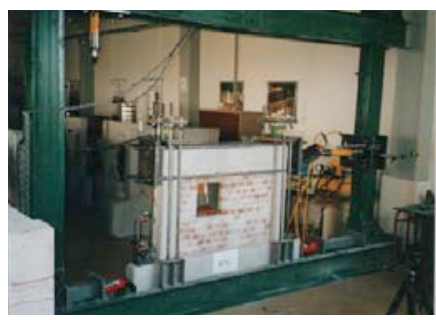

(c)

Fig. (4a). Reinforcement detailing of specimens (dimensions in $\mathrm{mm})$, (b) specimen with window opening, and (c) instrumentation, and test setup[6].

The failure mechanisms of the individual masonry zones formed by the wall segments flanking the openings being

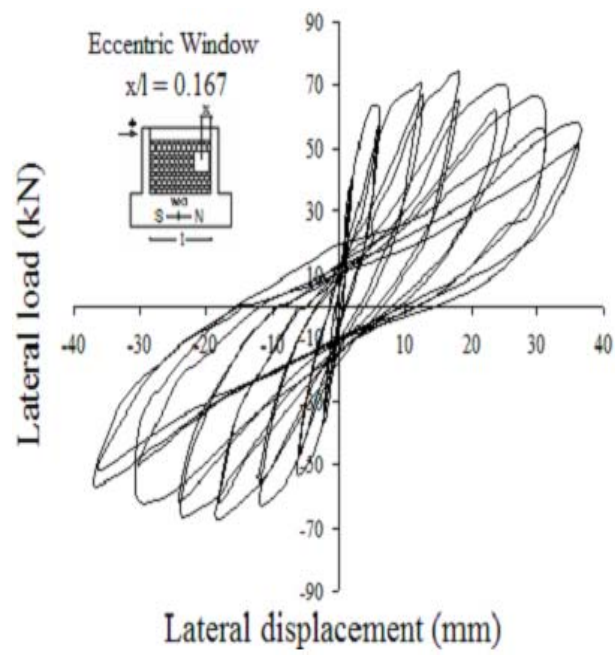

(a)

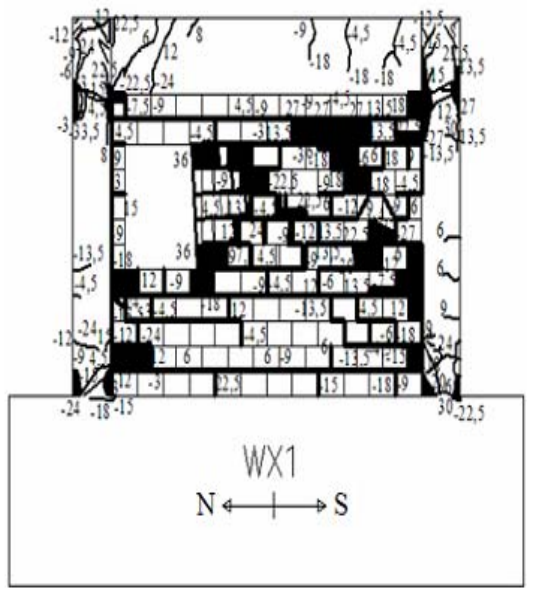

(b)

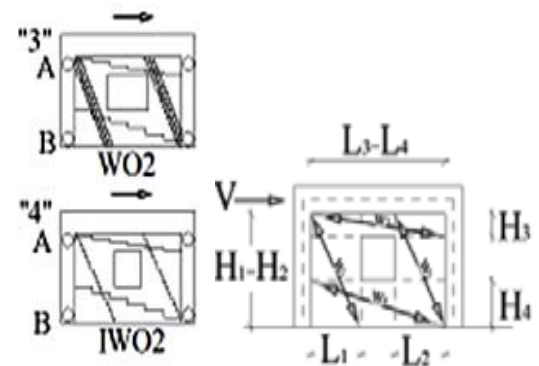

(c)

Fig. (5a). Lateral load - displacement hysteresis curves, (b) failure mode of infilled frame specimen with window opening for $x / l=0.167$, and (c) formation of wall segments flanking the opening being loaded diagonally, correspondng mechanism of secondary struts [6]. 
loaded diagonally are shown in Fig. (5c). A system of compressive struts was proposed within the frame, and analytical formulae were suggested to evaluate the lateral resistance $V_{u}$ of the identified failure mechanisms of the infilled frames with window openings. In order to perform a step-by-step force-displacement response analysis or dynamic time history analysis of large buildings with masonry infilled RC frames, a continuous force - deformation model based on an equivalent strut approach was proposed for masonry infill panels containing window openings.

A detailed experimental program was conducted by [8] to investigate the in-plane seismic behavior of steel frames with clay brick masonry infills having openings. Authors tested six large scales, single story and single bay frame specimens under in-plane cyclic loading applied at roof level. Masonry infills having central openings of various dimensions were included in the study. The pier width with respect to spandrel beam depth of the infill panel and opening type were the main test parameters. Six large-scale single-story single-bay steel frames were constructed and tested under cyclic quasistatic lateral in-plane loading and they were $2400 \mathrm{~mm}$ long by $1870 \mathrm{~mm}$ high. The infill panel thickness was $110 \mathrm{~mm}$ and they used single wythe. Among the specimens one was without any infill and one with a solid infill. Fig. (6a) illustrates the geometry and dimensions of the test specimens and Table $\mathbf{2}$ summarizes the properties of each specimen.

The specimen $P W 4$ had steel bar ties $10 \mathrm{~mm}$ diameter and $300 \mathrm{~mm}$ length, these were similar to ties used in current building construction to stabilize the slender side piers and possibly prevent out-of-plane failure. Lintel beams extending on each side $(150 \mathrm{~mm})$ were used to span openings. The test setup, including the loading system and specimen and reaction frames, is shown in Fig. (6b). The lateral cyclic load was applied by two $1000 \mathrm{kN}$ hydraulic actuators on either side of the specimen. Several YEFLA-5 strain gauges and LVDTs were installed and testing was conducted in displacement control. A cyclic displacement history which was predetermined and similar to that specified by the Applied Technology Council [9] for cyclic load testing of steel structural elements and configurations was imposed on each test specimen.

Table 2. Properties of Test Specimens [8]

\begin{tabular}{|c|l|}
\hline Specimen & \multicolumn{1}{|c|}{ Configuration } \\
\hline \hline BF & Bare frame \\
\hline SW & Solid infilled frame \\
\hline PW1 & Infilled frame with $500 \times 500 \mathrm{~mm}$ window opening \\
\hline PW2 & Infilled frame with $700 \times 800 \mathrm{~mm}$ window opening \\
\hline PW3 & Infilled frame with $1200 \times 600 \mathrm{~mm}$ window opening \\
\hline PW4 & Infilled frame with $700 \times 1450 \mathrm{~mm}$ door opening \\
\hline
\end{tabular}

The third specimen $(P W 1)$ tested was a frame with a masonry infill panel having a $500 \times 500 \mathrm{~mm}$ central window opening. The load-displacement relationship and the cracks are shown in Fig. (7a). The peak load for the specimen was
$176 \mathrm{kN}$ at a displacement of $+15 \mathrm{~mm}$. At this displacement, corner crushing of the infill top left corner as well as some bricks spalling along the compression strut in the left pier were observed Fig. (7b). Contrary to observations by other researchers, masonry infill having a central opening was not more ductile than solid infill which was tested earlier. $P W 2$ the specimen with masonry infill panel having a $700 \times 800$ $\mathrm{mm}$ window opening, which was designed to investigate the lateral load behavior of masonry infills with wide pier and shallow spandrel beam showed the peak load of $152 \mathrm{kN}$ at a displacement of $+15 \mathrm{~mm}$. Similar to specimen $P W 1$, this specimen was also not more ductile than solid infills.

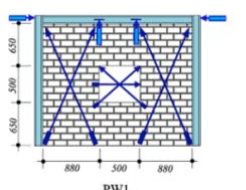

$\mathrm{PW} 1$

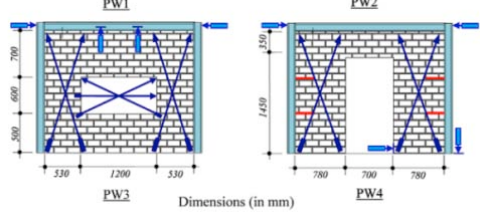

(a)

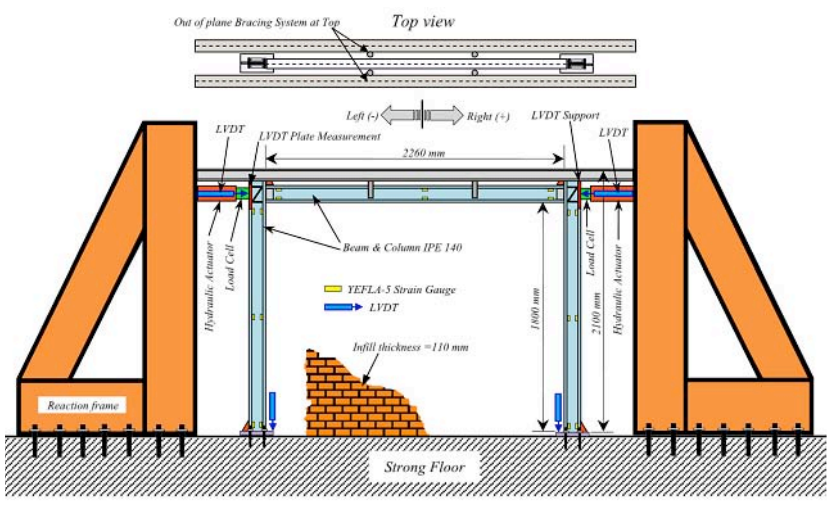

(b)
Fig. (6a). Configuration and position of LVDTs and DPC electrical transducers of test specimens, and (b) schematic view of test setup [8].

Specimen $P W 3$ had a $1200 \times 600 \mathrm{~mm}$ window opening and designed to investigate the lateral load behavior of masonry infills with narrow pier and deep spandrel beam was tested next. A combined stair-stepped-vertical crack was developed from the window's bottom right corner towards the infill bottom right compression corner; similar to other specimens was observed in this specimen also. The peak load for the specimen was $137 \mathrm{kN}$ at a displacement of $+15 \mathrm{~mm}$. PW3 specimen was also less ductile than specimen with solid infill. Specimen $P W 4$ had a door opening similar to that of specimen $P W 2$ in size and location with the exception of no bottom spandrel. Three compression struts are generated which is evident from Fig. (8a). The peak load for the specimen was $122.5 \mathrm{kN}$ at a displacement of $-10 \mathrm{~mm}$. The test was terminated because of the excessive out of plane deflection of the infill piers.The response comparison of all specimens in the form of envelope of a load-displacement relationship is plotted in Fig. (8b). Clearly, masonry infill 
Table 3. Effect of Openings On Post Peak Load and Deformation Ratios [8]

\begin{tabular}{|c|c|c|c|c|c|c|c|c|}
\hline Specimen & $\boldsymbol{H}_{t}$ & $\boldsymbol{H}_{u}$ & $\Delta$ & $\Delta$ & $\delta$ & $\delta$ & $\boldsymbol{R}_{H}=\boldsymbol{H}_{u} / \boldsymbol{H}_{t}$ & $\boldsymbol{R}_{\Delta}$ \\
\hline \multirow{2}{*}{ SW } & +201.5 & +165.1 & +20.1 & +60.1 & +1.1 & +3.2 & 0.82 & 2.99 \\
\hline & -212.1 & -169.1 & -20.6 & -50.3 & -1.1 & -2.7 & 0.80 & 2.44 \\
\hline \multirow{2}{*}{ PW1 } & +176.1 & +134.8 & +15.3 & +45.1 & +0.8 & +2.4 & 0.76 & 2.95 \\
\hline & -176.0 & -123.6 & -15.1 & -45.2 & -0.8 & -2.4 & 0.70 & 2.99 \\
\hline \multirow{2}{*}{ PW2 } & +151.9 & +77.8 & +15.4 & +40.4 & +0.8 & +2.2 & 0.51 & 2.62 \\
\hline & -138.9 & -103.9 & -15.1 & -35.2 & -0.8 & -1.9 & 0.75 & 2.33 \\
\hline \multirow{2}{*}{ PW3 } & +137.0 & +102.4 & +15.1 & +50.5 & +0.8 & +2.7 & 0.75 & 3.34 \\
\hline & -123.4 & -78.8 & -15.1 & -49.1 & -0.8 & -2.6 & 0.64 & 3.25 \\
\hline \multirow{2}{*}{ PW4 } & +116.5 & +80.6 & +15.2 & +47.8 & +0.8 & +2.6 & 0.69 & 3.14 \\
\hline & -121.2 & -83.1 & -15.0 & -48.6 & -0.8 & -2.6 & 0.68 & 3.24 \\
\hline
\end{tabular}

greatly increased the in-plane stiffness and shear resistance of steel frames. Stiffness and strength of specimen SW were 6.15 and 3.06 times respectively greater than those of specimen BF.

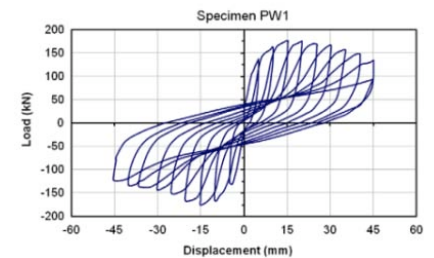

(a)
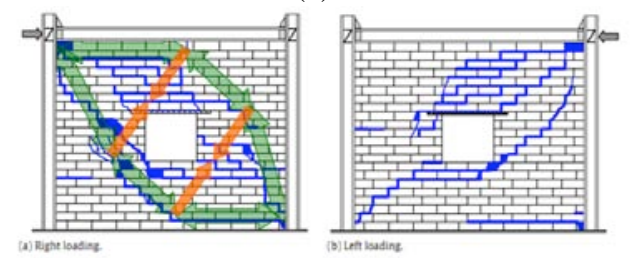

(b)

Fig. (7). (a) Load-displacement relation for specimen PW1, and (b) failure modes of specimen PW1 and the activated stress fields [8].
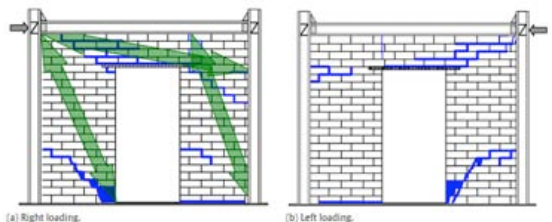

(a)

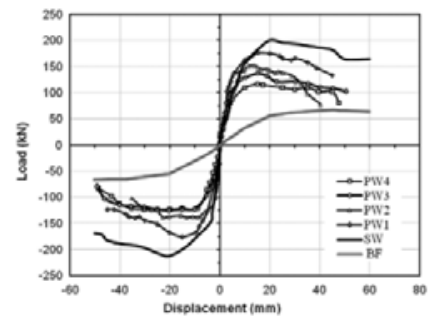

(b)

Fig. (8a). Failure modes of specimen PW4 and the activated stress fields, and (b)load-displacement envelopes [8].
Table 3 summarizes key values for load $(H)$, deformation $(\Delta)$ and drift $(\delta)$ parameters for the specimens. The signs + and - refer to positive and negative directions, respectively, and the subscripts $p$ and $u$ stand for peak and ultimate values. Moreover, two dimensionless parameters, $R_{H}$ and $R_{\Delta}$, are defined as the post peak load and deformation ratios, respectively. The post peak deformation ratio $\left(R_{\Delta}\right)$ is defined as the ratio of ultimate displacement to the displacement corresponding to the peak load that measures the displacement ductility of the specimens. Results show that openings in the panels tested do not lead to a more ductile behavior. The intensity of stiffness degradation for all specimens with an opening seems to be the same at early stages of elastic behavior. This indicated its independency to the opening aspect ratio.

An experimental investigation was carried out by Mosalam et al. [10] on gravity load designed steel frames under quasi static loading. The steel frames with semi rigid connections were infilled with unreinforced masonry. To permit continuous testing beyond the peak load carrying capacity, deformation controlled method was used. Quarter scale models were used during the experiments and the characteristics of all the specimens are summarized in Table 4. For two bay specimens, the load was applied at the top of the central column and in case of single bay specimen the load was applied at the center of the top beam. The point of application of load was selected to preserve the symmetry of loading. The experimental layout is shown in Fig. (9). After the steel frame was completed, the infill walls were constructed using $1 / 4$ scale concreteblocks. No shear connectors were used in any of the specimens and reinforced masonry beams were used on top of the openings. Effect of repeated loading on the strength and stiffness degradation was monitored during the tests. Sets of 3 cycles of the same displacement amplitude were applied and the displacements were gradually increased through each set. Two groups of displacement cycles were used namely $\mathrm{A}$ and $\mathrm{B}$, the second group, i.e. the group B was used to study the performance of the structure with previously cracked walls under earthquake like loading. Applied displacement patterns are shown in Figs. (9a and 9b). 
Table 4. Details of All the Specimens [10]

\begin{tabular}{|c|c|c|c|c|c|c|c|c|}
\hline Specimen & Bays & Openings & $\left(f_{b}\right)^{c}$ & $\left(f_{\text {oyt }}\right)^{d}$ & $f_{b} / f_{\text {oyt }}$ & $\left(f_{p}\right)^{e}$ & $\left(E_{p}\right)^{f}$ & $G_{m} / E_{p}$ \\
\hline \hline S1-N & 1 & None & 13.1 & 10.0 & 1.31 & 12.4 & 5,500 & 0.5 \\
\hline S2-N-I & 2 & None & 13.1 & 14.8 & 0.88 & 13.8 & 5,700 & 0.26 \\
\hline S2-N-II & 2 & None & 19.3 & 11.7 & 1.65 & 16.5 & 6,100 & 0.45 \\
\hline S2-ASYM & 2 & Asymmetric $^{a}$ & 19.3 & 11.7 & 1.65 & 16.5 & 6,100 & 0.45 \\
\hline S2-SYM & 2 & Symmetric $^{b}$ & 27.6 & 21.4 & 1.29 & 22.8 & 10,300 & 0.47 \\
\hline
\end{tabular}

${ }^{a}$ Windows and doors; ${ }^{b}$ Windows; ${ }^{c}$ Block compressive strength based on net area in MPa; ${ }^{d}$ Mortar cylinder compressive strength in MPa; ${ }^{e}$ Masonry prism strength $f_{p}$ based on face shellarea in $\mathrm{MPa} ;{ }^{f}$ Masonry prism stiffness $E_{p}$ based on face shellarea in MPa.

Cracks in specimens with openings initiated at the corners of the openings and then propagated towards the loaded corners. Dimensionless parameters $H_{u}$ (post cracking force ratio) and $D_{u}$ (deformation ratios) were defined. It was observed that the presence of opening reduced the solid infill stiffness values by about $40 \%$ for lateral loads below the cracking load level. The openings in infill walls lead to a more ductile behavior and large post cracking force ratio and this can be noted from Table 5. Also as the opening size increased, even in the case of asymmetric arrangement of openings, the post cracking force and deformation ratio followed the same pattern of small openings.On the application of second group of displacement cycles it was found that ultimate load capacities of solid infills with windows were similar. The presence of a door opening in one wall reduced the peak capacity by about $20 \%$.

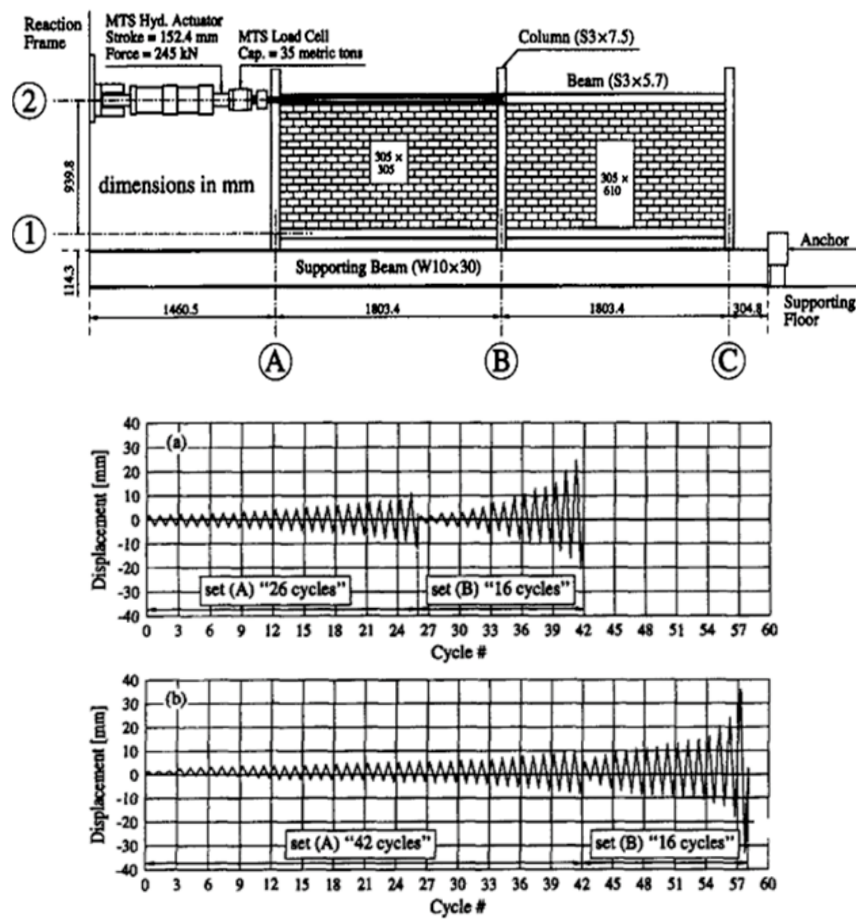

Fig. (9). Experimental setup of quasi-static tests for specimen S2ASYM, and displacement patterns applied quasi-statically for specimens S2-N-II and S2-SYM (a) and for specimen S2-ASYM (b) [10].
Large scale study was conducted on the behavior of masonry infilled steel frames by carrying out tests on twenty eight models [11]. In-plane horizontal load was applied at the roof level of these frames. Authors altered many parameters during the test, the interface conditions between frame and infill and the effect of column-panel ties are some of them. The effects of opening in masonry on the strength and stiffness of the frame was also a part of the investigation. In panels with openings, lintel beams were used; two deformed bars were placed in grouted bond beam blocks which were used to span the openings. Masonry units consisted of 200x200x400 mm nominal dimension hollow concrete blocks (54\% solid). Each specimen was constructed directly in the loading frame as shown in Fig. (10a) and the load was applied horizontally at roof level by means of $1800 \mathrm{kN}$ capacity ram. Lateral bracings were provided to prevent deflection in the out of plane direction and LVDTs were installed at the top of the columns. Dial gauges were set up at other points around the frame and inclinometers were used to measure the rotations of the column. Strain gauges were installed within the masonry panel along the compression diagonal. Load was applied gradually in increments of $22.2 \mathrm{kN}$ and the loading was not cyclic in nature. Most specimens were loaded continuously up to load-point deflection of approximately $25 \mathrm{~mm}$ to ensure that the frame remained elastic and reusable.

The load deflection curves of specimens with openings are shown in Fig. (10b). Among the specimens WC3 to WC6 and WD5 were specimens with openings, and WC3 and WC4 had centrally located door openings. No drop in load was observed at the time first cracks appeared. When the opening was moved towards loading side as in WC5, it lowered the ultimate load. WC6 had the opening moved away from the loading side and had the highest ultimate load among the panels with openings.

This contradicted some findings by others prior to this study.WD5 was similar to WC3 and WC4 except for the fact that it had vertical reinforcement around the opening as shown in Fig. (10c). This additional reinforcement had little or no effect on the strength and cracking characteristics. Cracks occurred primarily through horizontal joints at the level of the top of the opening in panels with central opening. As loading was increased, very large and wide cracks developed at the base of the panel. In WD5 the reinforcement provided resulted in diagonal cracking of the sub panels. Authors suggested possible location for door opening as 
Table 5. Effect of Openings on Post-cracking Force and Deformation Ratios [10]

\begin{tabular}{|l|c|c|c|c|c|c|}
\hline Specimen & $\boldsymbol{P}_{\boldsymbol{c} r}(\mathbf{k N})$ & $\Delta_{c r}(\mathbf{m m})$ & $\boldsymbol{P}_{u}(\mathbf{k N})$ & $\Delta_{v}(\mathbf{m m})$ & $\boldsymbol{H}_{u}$ & $\boldsymbol{D}_{u}$ \\
\hline \hline S2-N-11 & 42.7 & 6.6 & 44.0 & 17.5 & 1.03 & 2.65 \\
\hline S2-SYM & 29.4 & 7.6 & 42.3 & 23.9 & 1.44 & 3.13 \\
\hline S2-ASYM & 20.0 & 5.6 & 34.7 & 30.7 & 1.73 & 5.50 \\
\hline
\end{tabular}

the center of the panel. Vertical reinforcement around the opening increased the initial stiffness but it did not play any role in major crack load or ultimate strength.

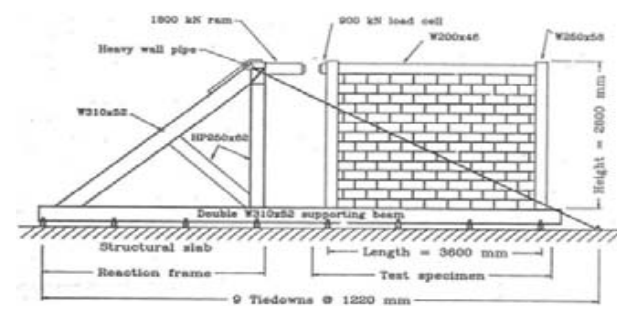

(a)

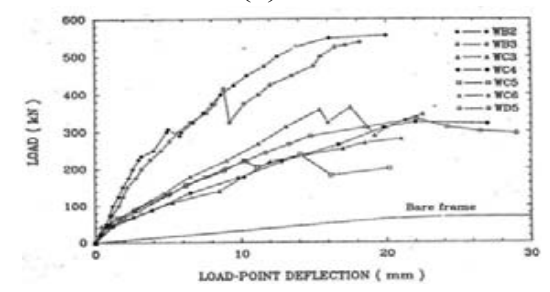

(b)

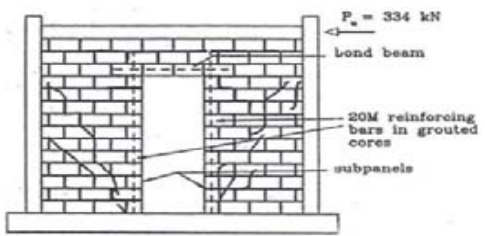

(c)

Fig. (10). (a) Test setup, (b) Load-deflection curves, and (c) Crack patterns for specimen WD5 with reinforced central doorway opening [11].

Experimental investigation was conducted by Schneider and Favieri [12] to understand strength, stiffness, strut formation and ductility of the infilled frames with extensive cracking in the masonry. Authors used test parameters like height-to-width aspect ratio of the masonry pier and the number of wythes. The most important influences on the seismic resistance of the complex structural system in an infilled frame were identified as the strut behaviour of the masonry infill, flexural stiffening due to the masonry piers and stiffening of the beam-to-column joint. The test setup and the reaction system are shown in Fig. (11a). All tests were conducted in the Newmark structural engineering lab at the University of Illinois. The chosen test specimen represented an interior steel column with masonry piers constructed using clay unit masonry placed on each side of the steel column. Window openings were replicated by the ab- sence of thrust that can develop in the masonry over the window opening height $(h)$. The schematic diagram of a test specimen is shown in Fig. (11b).

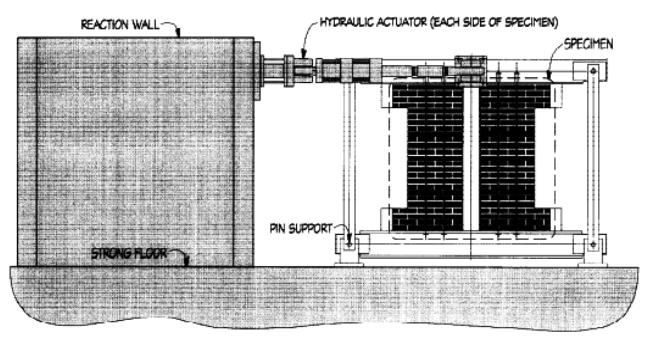

(a)

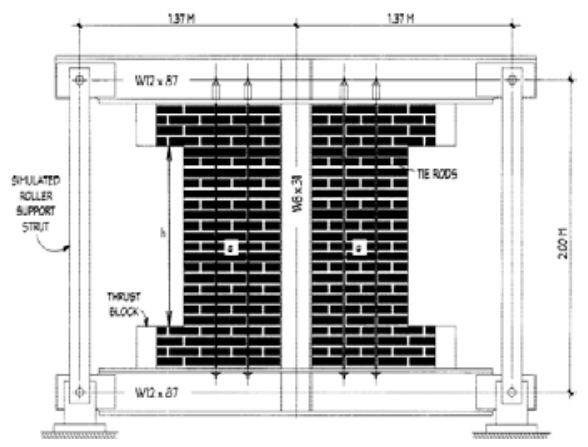

(b)

Fig. (11). (a) Test setup, and (b) Schematic diagram representing a test specimen [12].

The primary parameters for the investigation were the width $(a)$ for each side of the masonry infill and the number of wythes. The pier height was fixed with a window opening height of $1.15 \mathrm{~m}$. To determine the distribution of the lateral forces in each element, load cells, displacement transducers and strain gauges were placed on the test frame. Earthquake loads were simulated by imposing lateral deformation to the center of the upper beam using two $500 \mathrm{kN}$ actuators, one on each side of the specimen.Predetermined cyclic deformations were imposed on each specimen and a typical deformation history is shown in Fig. (12a), the actuators maintained equal loads to avoid torsion. Masonry force-displacement behaviour was plotted Fig. (12b and 12c), the horizontal load on the test specimen was the sum of the forces in both the actuators and the displacement was measured at the mid-depth of upper beam. Bare frame was tested before placing masonry to study the inelastic behaviour of the masonry alone and the results were used for comparative study of the infilled frame. Two elastic deformation cycles were imposed after the three cycles of same amplitude drift. After each test, the permanent lateral-displacement was corrected to obtain the original unreformed configuration. 
Table 6. Maximum Average and Peak Shear Strength Values of Masonry Infill [13]

\begin{tabular}{|c|c|c|c|c|c|c|}
\hline \multirow[t]{2}{*}{ Test specimen } & \multicolumn{2}{|c|}{$\begin{array}{c}\text { Maximum average values of shear } \\
\text { strength }\end{array}$} & \multicolumn{3}{|c|}{ Peak values of shear strength } & \multirow[t]{2}{*}{$\begin{array}{l}\text { Average to-peak } \\
\text { shear ratio }\end{array}$} \\
\hline & Force $(\mathbf{k N})$ & Stress (MPa) & Force $(\mathbf{k N})$ & Stress (MPa) & Drift (\%) & \\
\hline $40 \mathrm{~W} 2$ & 155.8 & 1.075 & 182.0 & 1.261 & 1.38 & 0.856 \\
\hline $60 \mathrm{~W} 1$ & 111.3 & 1.027 & 126.4 & 1.164 & 1.07 & 0.880 \\
\hline 80W1 & 152.6 & 1.054 & 182.5 & 1.261 & 0.93 & 0.837 \\
\hline
\end{tabular}

Fig. (12b). illustrates the contribution of the masonry infill to the strength of the steel masonry composite system. Results for this hysteretic behaviour were obtained by subtracting the bare steel frame results from those of the composite test specimen. Contribution of the double wythe wall was almost twice the strength contributed by single wythe wall. Even at smaller drift levels, compared to double wythe wall, the contribution of single wythe walls diminished significantly; however, at maximum drifts little contribution was observed in both the cases. The test setup used for the investigation was different as compared to previous studies and the limitations like the position of opening, confinement of masonry are notable.

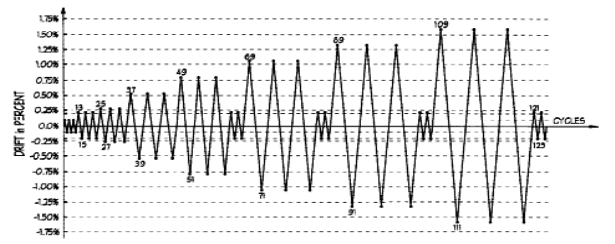

(a)

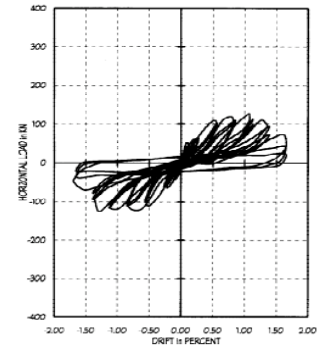

(b)

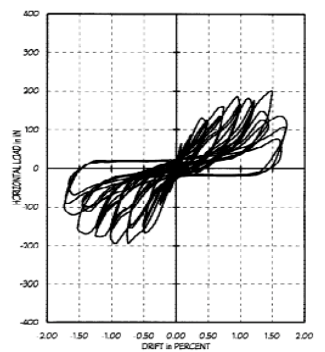

(c)
Fig. (12). (a) Imposed cyclic deformation history, (b) and (c) force displacement behaviour of specimen 2 and 3 [12].

As an extension of the previous study, infill strength and stiffness deterioration was studied by Schneider et al.[13] for steel frames with unreinforced masonry infills having large window openings. To correlate the damage of the masonry infill to the lateral strength and stiffness that can be expected from the structural system when subjected to large-amplitude drift was the primary object of the tests. Five large scale steel frame masonry infill specimens were tested by imposing inplane lateral deformations at the floor level. Test parameters included the pier width of the infill between the steel column and the window opening, and the number of wythes of unreinforced masonry. Of particular interest was the strength and stiffness of the brick masonry infill over a wide range of drift amplitudes. Fig. (11a) shows the specimen and reaction wall system for this test program. Large displacement cycles were imposed on the bare steel frame to approximate equivalent amplitudes expected during each test. Three cycles of displacement for all deformation amplitude were imposed, up to a maximum $1.5 \%$ drift. Two elastic deformation cycles at amplitude of $0.20 \%$ drift were imposed between each set of three cycles of same amplitude drift. Fig. (13a) illustrates the extracted inelastic shear force-displacement behavior of only the masonry infill for all five test specimens. The first of the three same amplitude displacement cycles absorbed the most inelastic energy.

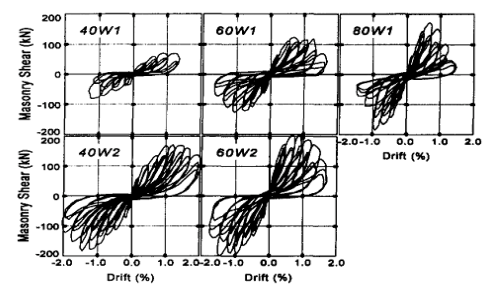

(a)

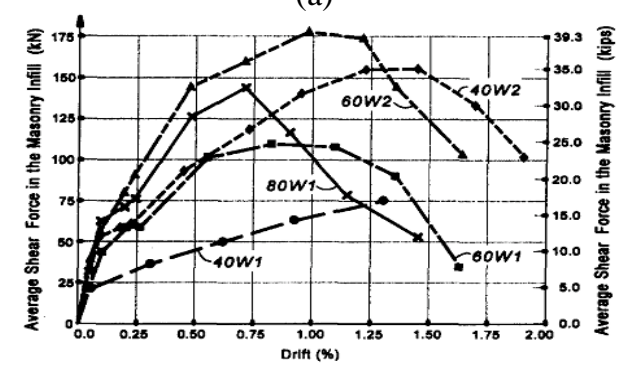

(b)

Fig. (13). (a) Horizontal shear forces in masonry, and (b) Average Shear Force versus Drift Envelope for Masonry Infill [13].

According to authors, for the second of the three sameamplitude displacement cycles, the deterioration in lateral strength varied among the infill specimens with drift amplitude, but strength reductions of $20-30 \%$ were not unusual. The envelope curves of the shear force deformation behavior for each infill specimen is shown in Fig. (13b). The shear force in this figure was determined as the average strength obtained from all three cycles at the given drift amplitude.These curves represent the shear strength that can be expected from the infill at various drift amplitudes after several cycles of inelastic deformation have been imposed. Maximum average values of shear force envelope curves are 
summarized in Table 6. The average shear strength of the masonry infills tested was between $0.82 \mathrm{MPa}$ and $1.08 \mathrm{MPa}$, with an average ultimate shear stress of $0.96 \mathrm{MPa}$. The effective stiffness showed a continuous degradation with imposed deformations. Depending on the pier width and the number of wythes, the shear force-deformation behavior of the masonry piers varied.

Voon and Ingham [14] tested eight partially grout-filled perforated concrete masonry walls that were subjected to cyclic lateral loading. According to authors New Zealand non-specific masonry design standard NZS4229 [15] unsafely over predicts the strength capacity of concrete masonry walls with small openings and an amendment is proposed to rectify this matter. The in-plane lateral strength of a masonry panel is specified in [15] through determination of its bracing capacity. Researches in this field indicated that the existing design standard may be conservative in its treatment of walls with openings. The eight walls of the study had variations in lintel reinforcement detailing, including detailing that complied with [15] and a range of penetration geometries. The geometries and reinforcement details of wall 1 is shown in Fig. (14a). All eight walls were constructed to a common height of $2,400 \mathrm{~mm}$ and were partially grout-filled, where only those cells containing reinforcement were grouted. All wall openings had a length of $600 \mathrm{~mm}$.

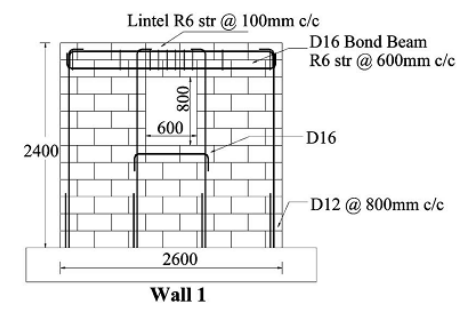

(a)

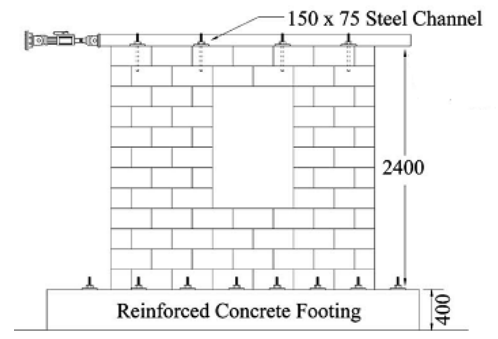

(b)

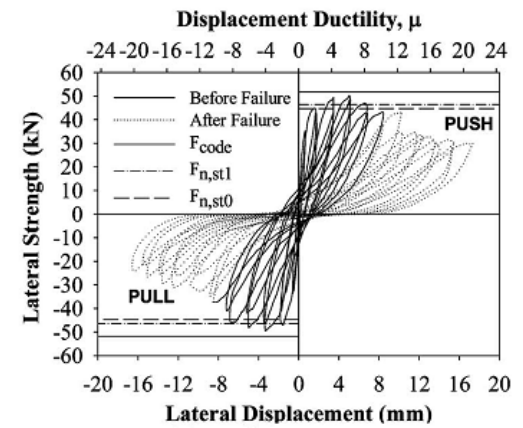

(c)

Fig. (14). (a) Wall 1 geometry and reinforcement details, (b) experimental set up for masonry wall with opening, and (c) Force displacement histories for wall 1 [14].
The testing of specimens reported herein was conducted according to the setup shown in Fig. (14b). Horizontal cyclic loading was applied to the top of the wall via a $150 \times 75$ steel channel as shown in Fig. (14b). A load cell to measure the magnitude of the lateral force was placed between the actuator and the steel channel.The experimentally obtained forcedisplacement curves for masonry walls Fig. (14c). depicted the lateral displacement at the top of the walls as a function of applied lateral shear force. Due to the lack of horizontal shear reinforcement and the fact that the walls were partially grout-filled, all test walls were observed to fail in a diagonal tension mode. The maximum strength was typically developed during the first excursion till displacement ductility level of 4 .

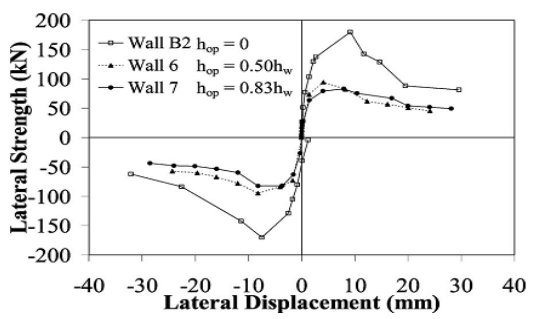

(a)

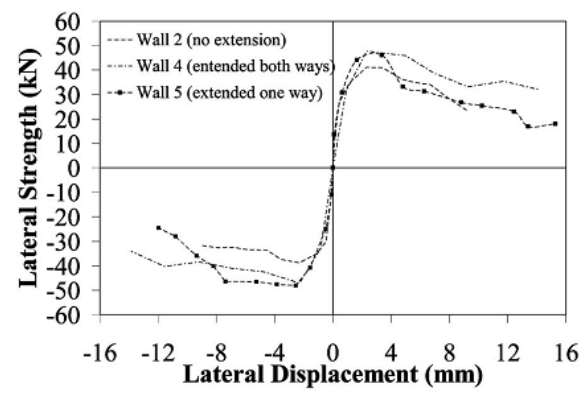

(b)

Fig. (15). (a) Effect of openings on wall strength (shown for pull direction), and (b) effect of trimming reinforcement on 2,600 mm long perforated masonry walls [14].

The partially grouted walls exhibited only gradual strength and stiffness degradation despite the presence of widely open diagonal cracks, and in no case did any wall suffer from sudden failure. From the wall cracking patterns, it was clear that the absence of major damage in the solid grout-filled bond beam supported the notion of frame-type action being developed at a later stage of testing. It was observed during experimental testing that the 4,200 $\mathrm{mm}$ long masonry walls displayed greater cracking than the $2,600 \mathrm{~mm}$ long walls. Consequently, it was deduced that the lower observed ductility rating for the 4,200 $\mathrm{mm}$ long walls occurred because of the rapid developing wide cracks that contribute to shear displacement, accelerating initiation of the diagonal tension mode of failure and subsequent strength degradation.It was concluded that [15] is only non-conservative for window openings having a height of less than $1,200 \mathrm{~mm}$, though unfortunately this probably accounts for a significant proportion of window geometries. Due to the lack of distributed horizontal shear reinforcement and the fact that the wall was partially grout-filled, all test walls were observed to fail in diagonal tension mode. Test results successfully illustrated correlation between the reduction of wall strength and the 
increasing height of wall openings. This reduction of wall strength is also identified in the force-displacement envelopes presented in Fig. (15a).

Experimental results illustrated that the use of extended D16 trimming reinforcement affected wall strength considerably. This increase of wall strength can also be identified in the force displacement envelopes presented in Fig. (15b). The force-displacement envelopes in Fig. (15) clearly illustrates the increase of lateral strength from the maximum of $41.2 \mathrm{kN}$ for Wall 2 to $47.7 \mathrm{kN}$ and $52.4 \mathrm{kN}$ when the trimming reinforcement was extended beneath the window opening in Walls 4 and 5, therefore, resulting in strength increase of about $18 \%$ and $27 \%$, respectively.For the small window opening in Wall 1, the measured strength was slightly less than that prescribed by NZS4229.

Structural behavior of framed masonry walls subjected to in-plane monotonic loading was studied by Chiou et al. [16]. Full scale test and discontinuous deformation analysis (DDA) was carried out in this study. Structural behavior and stress distribution of the masonry showed that the characteristic of the masonry structure is highly influenced by the failure of mortar. Partially filled RC frame was tested to study the short column effect. Framed masonry walls are constructed with brittle materials and the failure of walls are frequently initiated from the cracking of mortar and separation of bricks, which in turn causes discontinuous and nonlinear behavior. The cracking and separation phenomena occurring in the masonry structure cause distinct block elements. Earlier discrete element method (DEM) was used to study masonry structures under dynamic load. The method proved to be time consuming and complex and thus paved for another method namely discontinuous deformation analysis (DDA). DDA also was not a method which could provide a complete solution as it was less efficient for continuous structures. DDA is refined by the concept of artificial joints in this study and the test arrangement is shown in the Fig. (16a). Three specimens with dimension $320 \times 300 \mathrm{~cm}$ were tested: $\mathrm{RC}$ bare frame, partially filled $\mathrm{RC}$ frame, and fully filled RC frame. In case of partially filled frame, the masonry infill had height of $110 \mathrm{~cm}$. A wooden window was provided in the opening area Fig. (16b), but the same was neglected in the numerical model. Monotonic loading was applied in this study and the load-deflection relation of partially filled RC frame is presented in Fig. (16c). The experimental results and DDA results were almost matching but as window was neglected in the numerical model, DDA predicted larger deflections. During the test of partially infilled frame, it was observed that failures concentrated on RC frames and no obvious crack was found in the masonry. Horizontal cracks were found to concentrate on the center region of the left column. Cracks were also observed at the left upper corner of the wall. Numerous cracks were also found on the top and bottom of the left column. Right column failure was similar to the one observed in the case of the $\mathrm{RC}$ bare frame and some cracks were observed on the upper side of the beam. Different failure configuration in left beam in the partially filled masonry wall is due to the short column effect. The nonlinear constitutive relations of brick, mortar, and concrete were recommended to be considered in further studies. Furthermore, the out of plane failure of the masonry wall, the bond slip of reinforcements, and the effects of the energy release of fracture were also highly recommended to be fully studied in the future.

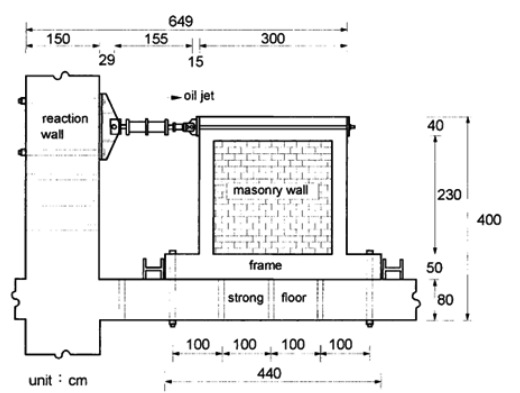

(a)

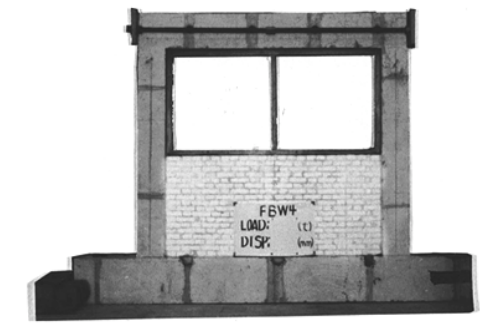

(b)

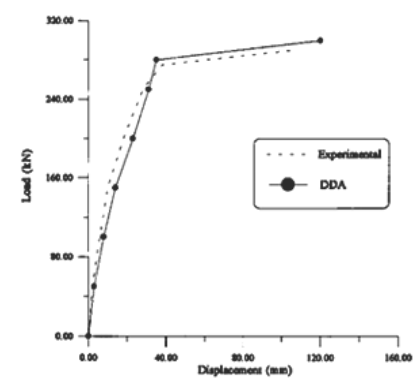

(c)

Fig. (16). (a) Test setup, (b) partially infilled RC frame with wooden window, and (c) Load-deflection relation of RC frame partially filled with masonry wall [16].

Behavior of infilled frame with opening was investigated by Sathyanarayan and Govindan [17] by carrying out tests on bare frames, fully infilled frames and frames with opening. Opening area of the infill was kept constant at $11.11 \%$ of the total infill area and ultimate loads and cracking loads were compared with the results from the elastic and plastic methods of analysis. To study the effect of vertical and horizontal loads on frames, diagonal loading was adopted as shown in Fig. (17a). Square infill frames were used in the study. Two sets of frames, each having three numbers of models, were cast and the frame dimensions were $50 \times 50 \mathrm{~mm}$ and $50 \times 70 \mathrm{~mm}$. In each set, a bare frame, a fully infilled frame and one with opening were tested; stiffeners were not provided around the opening of the infills. For the main reinforcement, $4 \mathrm{~mm}$ diameter bars of mild steel were used. $4 \mathrm{~mm}$ diameter bars at a spacing of $40 \mathrm{~mm}$ was used for stirrups and after 21 days of casting, available country bricks were used to infill the frames.

Vertical and horizontal diagonal deflection was measured by means of dial gauges and the inclined leg deflections were measured by using LVDTs Fig. (17a). Due to the composite action of the frame and the infill the load deflection curve Fig. (17b) is linear up to cracking of the infill. Princi- 
pal stresses were calculated at the selected grid points of the infill in the pre-cracking and at the cracking stages Fig. (17c).

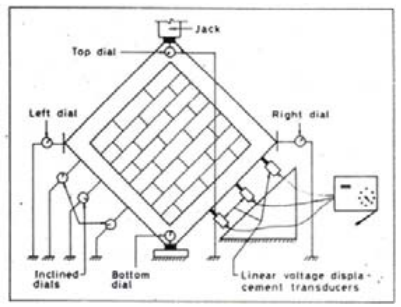

(a)
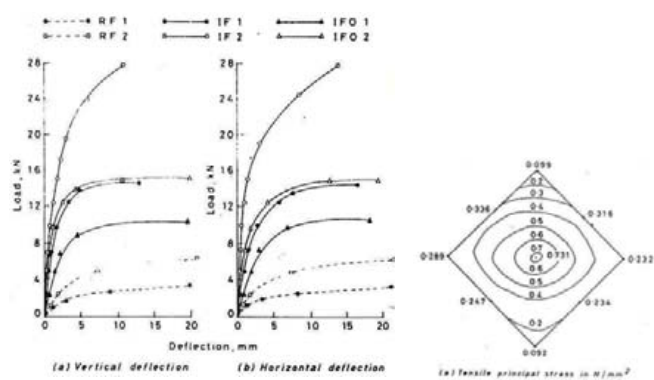

(b)

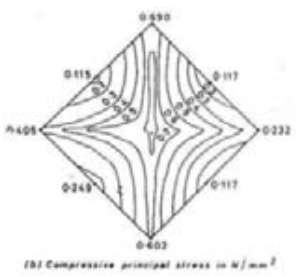

(c)

Fig. (17). (a) Test setup, (b) Load deflection curves for infilled frames, and (c) principal stress contours [17].

It is evident that vertically loaded diagonal acted as strut and horizontal diagonal was subjected to tension. Stiffness of vertical diagonal was calculated by drawing a tangent to the load versus deflection curve. The working load which is $50 \%$ of the ultimate load was found to be lower than the cracking load in the case of infilled frame without opening and also with opening. After the formation of diagonal cracking in the infill, the inclined legs of the frame started behaving like a beam. The increase in loading led to bending cracks in the frame and formation of hinges in the legs. Theoretical analysis was carried out by plastic theory proposed by Liauw and Kwan [18]. Provision of central square window opening increased the deflection at the same load compared to the infilled frame with no opening, but the deflections were found to be less in comparison with the bare frame. Also cracking was delayed in frame with opening when compared to bare frame. Though the opening in masonry wall reduced the stiffness of the frame, it was still stiffer than the bare frame. Authors suggested use of ferro-cement in the brick infill to prevent spalling and designing frame to give sufficient warning before failure.

\section{Experimental Assessment: Improving Lateral Load Per- formance}

The experimental work carried out by Mohammadi et al. [19] was primarily aimed at discovering methods to improve ductility of infilled frames by testing six singlestory singlebay infilled steel frames. In the first stage, along with 5 other specimens, authors tested one specimen with corner openings at the top. The loads were applied manually using two horizontal hydraulic jacks, installed on supporting frames in opposite directions, as shown in Fig. (18a). The rate of loading was quick enough to avoid creeping and other undesirable effects, but slow enough to be considered to be static load. The specimens were subjected to five loading cycles, with amplitudes of 10, 20, 30, 40, and $50 \mathrm{~mm}$, respectively (the first amplitude was chosen in such a way as to observe diagonal cracking in specimens). A technique tested to raise ductility was to remove the infill corners, in order to transfer the failure to the frame elements, especially to the beam, which is normally weaker than the columns. In this regard, two specimens were tested, both having a three layer infill, composed of a $10 \mathrm{~mm}$ thick masonry wall with a $25 \mathrm{~mm}$ concrete layer on both sides. In the second specimen an opening was created at each top corner Fig. (18b); two sides of which were armored by a reinforced concrete material.

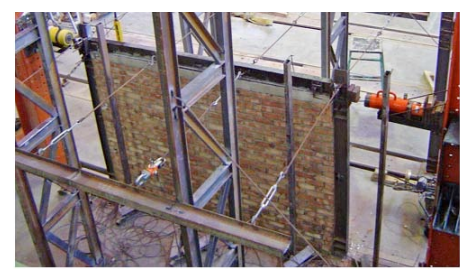

(a)

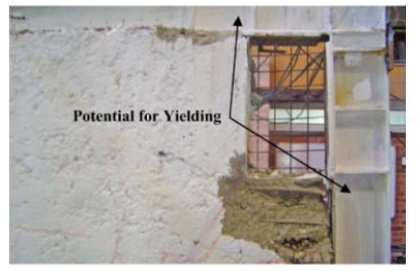

(b)

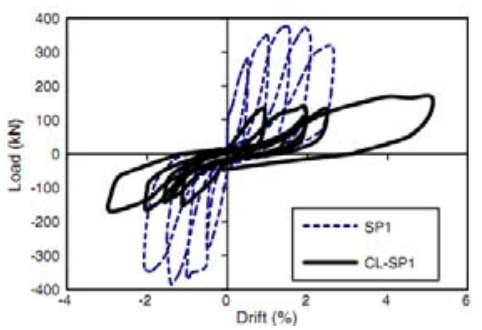

(c)

Fig. (18). (a) Test setup, (b) failure in CL-SP1 under the opening, (c) load-displacement behavior of the specimens SP1 and CL-SP1 [19].

In the specimen with opening, it was expected that the column or beam would yield in segments in the vicinity of the opening aspresented in Fig. (18b) as "potential for yielding".However, the armored parts under the openings of both top corners crushed in the third cycle, as shown in Fig. $(\mathbf{1 8 b})$. The loading was terminated after the specimen exceeded the drift of $5 \%$, which was greater than the normal drift demand, regardless of the fact that loss of strength was not observed.Cyclic load displacement plots monitoring the overall lateral drift were generated for each specimen Fig. (18c). The hysteretic loops for specimen without opening 
(SP1) were symmetric in both loading directions, although this was not the case for the specimen with opening (CLSP1). In addition, the strength of this specimen was much lower than that of the one without opening in all cycles.

Colombo et al.[20] worked on provision for increasing the ductility and the energy dissipation capacity of masonry infill panels. Possibility of confining the infill panels by using polymeric grids was studied by testing two infill layouts with dimensions of $4.6 \times 2.6 \mathrm{~m}$. The panels were either without openings or with non-symmetrical openings (a door and a window). The results of full-scale in plane cyclic tests on panels confined with the grids are compared with the behaviour of the panels in the same configuration, but constructed by using the conventional technique. The specimens with solid infills and with infills containing non-symmetrical openings Fig. (19a) were tested under in plane cyclic loading. A three story steel frame already available at the ELSA (European Laboratory for Structural Assessment) was reused. The panels were constructed on the ground floor of the two parallel frames on a $0.55 \mathrm{~m}$ high concrete base in order to preclude any influence of the stiffeners at the base of the columns. Polymeric net had a $40 \times 40 \mathrm{~mm}$ ribbed mesh and the plastic material had strength of $30 \mathrm{kN} / \mathrm{m}$. The scheme adopted for the panel with openings is reported in Fig. (19b).

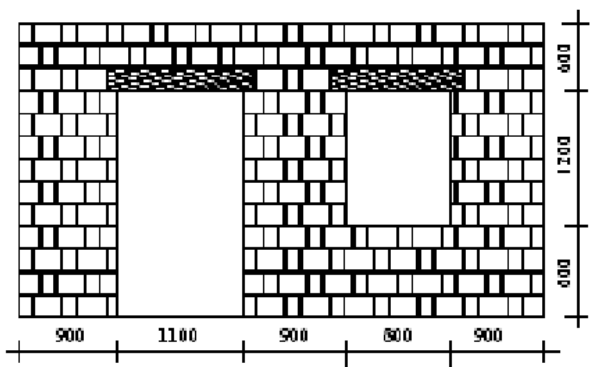

(a)

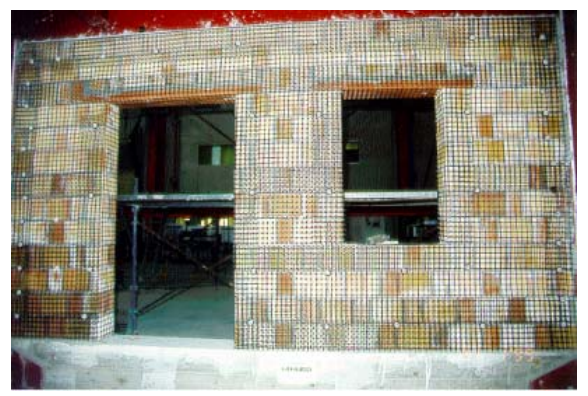

(b)

Fig. (19). (a) Layout of the panels with openings, (b) scheme of the plastic net for the wall with openings [20].

During testing, unreinforced infill totally collapsed at a displacement corresponding to a story rotation of about 0.03 radians. At this level of deformation the panel with the plastic grid, even though dramatically damaged Fig. (20b), was still able to provide $65 \%$ of its maximum strength. The effects of the confinement accomplished by the insertion of the net resulted in a significant shift of the yield point up to larger forces (40\% more) and larger rotations (from 0.006 to 0.015 radians) as shown in Fig. (20a). The comparison between the behaviour of the tested panels showed that the adoption of this methodology could strongly modify the strength-decay characteristics of the panels and was evident from the Fig. (20c).

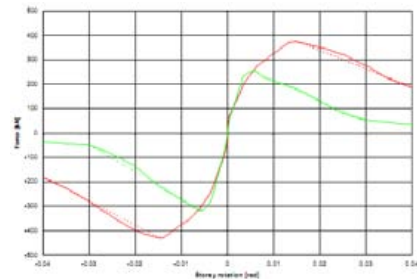

(a)

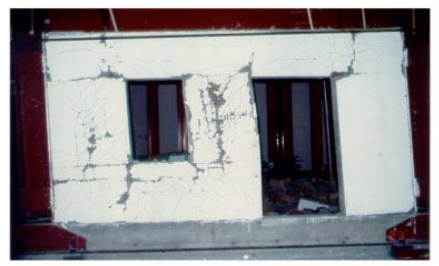

(b)

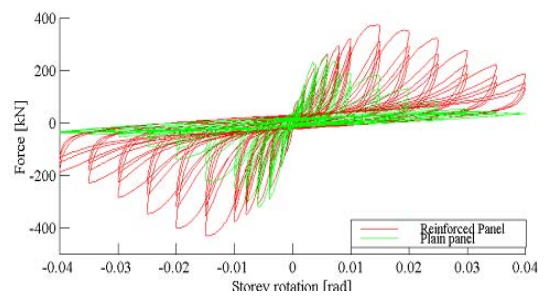

(c)

Fig. (20). (a) Envelope curves for infills with openings, (b) damage pattern in the panel with openings, and (c) comparison of cycles for plain and reinforced panels. Red curves denote reinforced panels and green curves denote plain panel [20].

Buonopane and White [21] carried out pseudo dynamic testing of a two-story, two-bay specimen built at half-scale Fig. (21). The story displacements at the center of the interior beam-column joints and displacement at the center of the base beam were measured by displacement transducers (DCDTs) mounted on an external reference frame. Twenty DCDTs measured total length changes across main and off diagonals of the masonry, and across window opening and a hydraulic actuator of capacity $245 \mathrm{kN}$ was used to apply story displacements.Free vibration and static flexibility tests were performed on the concrete frame before the infill was built and repeated again after construction of the infill to estimate modal frequencies and natural damping ratios. The final pseudo dynamic testing sequence subjected the specimen to a series of three additional Taft excitations of PGA $0.35 \mathrm{~g}, 0.55 \mathrm{~g}$, and $0.80 \mathrm{~g}$. The Taft $0.35 \mathrm{~g}$ excitation tested the behavior of the control algorithm with nonlinear stiffness caused primarily by separation between infill and frame.Significant damage and degradation of the infill and frame, comparable to that which might occur during major seismic events was produced by final test of $0.55 \mathrm{~g}$ and $0.80 \mathrm{~g}$. Fig. (22a) summarizes the story drift behavior of the infilled frame for increasing levels of excitation, showing normalized displaced shapes of the structure at the times of peak first story displacement. During the first three tests, the interstory drifts were about equal in each story, but the window openings in the upper walls made them less stiff. In the final $0.80 \mathrm{~g}$ test, the demand on the lower story exceeded its capacity and a rapid loss of stiffness allowed for the soft 
first-story response. The story drift-story shear relations are given in Fig. (22b). The first-story initial stiffness was observed to be $20.5 \mathrm{kN} / \mathrm{mm}$, and for the second story it was $5.1 \mathrm{kN} / \mathrm{mm}$. The stiffness increased sharply in response to the strut action induced in the infill once the structure had displaced sufficiently to close the gaps and produce contact between the frame and infill.

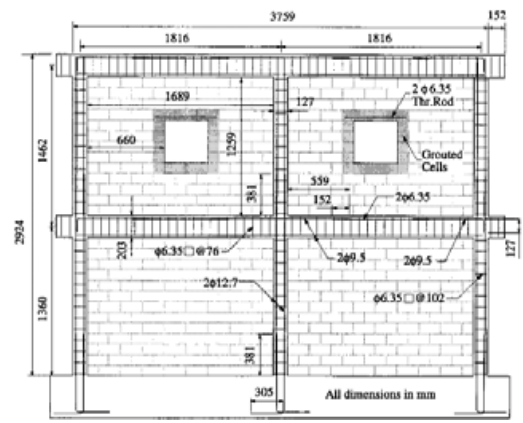

Fig. (21). Elevation of Half-Scale infill Specimen for PSD Testing [21].

The hysteretic energy was calculated from the area enclosed by each cycle in the story shear-drift plot, and was considered as a measure of damage to the specimen. Table 7 lists the total hysteretic energy levels and percentages in each story for each test. During the Taft $0.55 \mathrm{~g}$ test, the second story suffered significant diagonal cracking, yet showed no appreciable change in relative story hysteretic energy dissipation from the previous lower level tests.Moments and axial forces in the columns were computed from the strains recorded by pairs of strain gauges mounted on the reinforcing steel. Fig. (22c) shows moment and axial force diagrams for the Taft $0.55 \mathrm{~g}$ test at the time of maximum base shear. A substantial amount of shear force acted on the column from interaction of the frame and infill and is evident from the large slope of the moment diagram over the upper half of the column. Formation of a compressive strut originating near the loaded corner of the panel and sufficiently inclined to pass below the window opening might have caused large shear force. The test results give good insight into the behaviour of masonry infilled RC frames with openings in walls under dynamic loads, and subsequently to develop methods to improve the lateral load performance of such buildings.

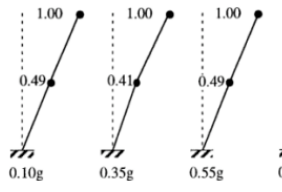

(a)
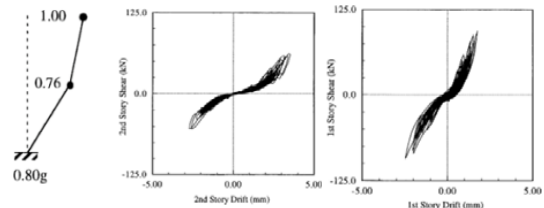

(b)

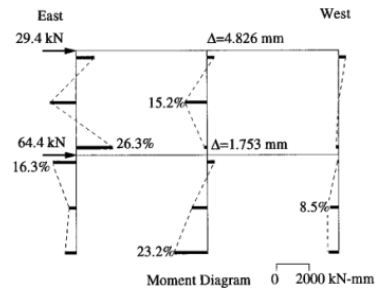

(c)

Fig. (22). (a) Normalized deflected shapes at peak first story displacements, (b) Taft $0.55 \mathrm{~g}$ story drift-shear relations, and (c) moment diagram for Taft $0.55 \mathrm{~g}$ at time of maximum base shear [21].
Table 7. Total Story Hysteretic Energy [21]

\begin{tabular}{|c|c|c|c|}
\hline PGA(g) & $\begin{array}{c}\text { Total hysteretic en- } \\
\text { ergy(Nm) }\end{array}$ & $\begin{array}{c}\text { First story } \\
(\boldsymbol{\%})\end{array}$ & $\begin{array}{c}\text { Second story } \\
(\boldsymbol{\%})\end{array}$ \\
\hline \hline 0.10 & 6.67 & 63 & 37 \\
\hline 0.35 & 399 & 65 & 35 \\
\hline 0.55 & 1593 & 66 & 34 \\
\hline 0.80 & 7129 & 81 & 19 \\
\hline
\end{tabular}

Analytical Assessment of Lateral Strength, Stiffness and Failure Modes

Stiffness of an infilled frame with openings has been calculated using a finite element method and was compared with experimental results by Mallick and Garg [4].Theoretical calculations were made separately for two types of frames; with and without shear connectors. The length of contact for frames without shear connectors was determined by using following formula given by StaffordSmith [22]:

$$
\frac{\beta}{l}=\frac{\pi}{2 \lambda l} ; \lambda=4 \sqrt{\frac{E_{0} t}{4 E I l}}
$$

Where $\beta$ is the unknown length of contact,lis length of frame, $E_{0}$ is modulus of elasticity of infill material, $E I$ is flexural rigidity of frame material, and $t$ is thickness of infill panel.For frames with shear connectors the infill material was assumed to be elastic, isotropic and homogeneous. During testing no separation or boundary cracks appeared between the frame and the infill. Thus the frame was imagined to be in contact with the infill all along the boundary except at the unloaded corner node points. The bounding frame is assumed to transfer the loads to the infill normal to the contact surface through the shear connectors. The energy due to axial deformation of the frame members was assumed to be predominant than the bending energy. The frame members were assumed to be hinged at their ends.This is based on the observation that $90 \%$ of the total stiffness of the infilled frame is due to the presence of the infill panel inside the frame.Fig. (23a) shows the idealization of the infilled frame with the infill panel built upon an assembly of 16 square plates and 12 beam elements so fixed together as to ensure compatibility of deformations at the node points and across the boundaries.

The stiffness matrix of each of these plate and beam elements in terms of global coordinates is assembled to yield the complete stiffness matrix of the composite frame. The assumption that the frame remained in contact with the infill at all node points except at the corners gave very high theoretical values of lateral stiffness. This was expected because in reality the infill panel is not rigidly connected to the frame members. The theoretical analysis was again modified by assuming that the interaction forces between the frame and the infill along their junction consisted only of normal forces. This assumption led to the consideration of both shear and axial displacement components for the windward column elements. However, for the frame elements of the girder and leeward column only shear deformation were con- 
sidered. The numbering of displacement components for forming the complete stiffness matrix, inline with the above discussion is shown in Fig. (23b). The consistent load vector, $Q$, was in the analysis; all the elements of $Q$ were zero except those relating to the node point where the external load is applied. Solving a system of linear equations, the generalized displacement vector, $q$, for the composite frame was obtained from: $q=k^{-1} Q$, which subsequently gave the stiffness of the system as:

$$
k=\frac{Q}{q}
$$

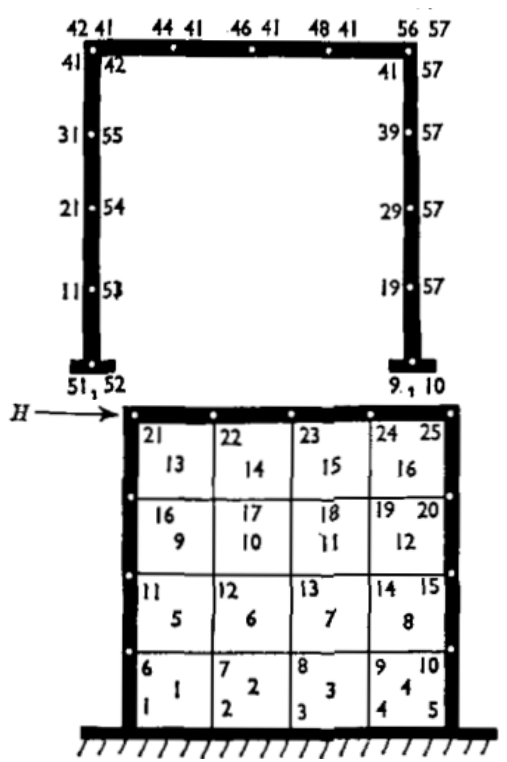

(a)

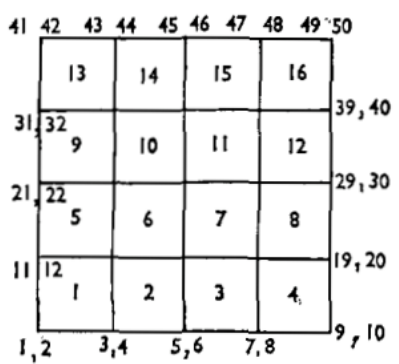

(b)

Fig. (23). (a) Idealization of the infilled frame, (b) numbering of displacement components for forming the complete stiffness matrix[4].

The analytical results (stiffness) obtained using the finite element method were compared with those obtained experimentally Table $\mathbf{8}$. The comparison shows that the error in analytical prediction of lateral stiffness of frames with masonry infills containing openings is not significant for most of the cases, both for frames without connectors and frames with connectors.

A finite element technique for the analysis of brick infilled RC frames was presented by Asteris [23]. The techinque was used to investigate the influence of openings in the infills on the reduction of stiffness of frame. The analysis was carried on single story single bay frame and parameters varied during the study was the percentage of opening and the position of the opening.The basic characteristic of the analysis technique was that the infill/frame contact lengths and the contact stresses were estimated as an integral part of the solution. For the analysis, a four-node isoparametric rectangular finite element model with 8 degrees of freedom was used. The material was assumed to be homogeneous and anisotropic. Modulus of elasticity in the xdirection $\left(E_{x}\right)$, direction parallel to the bed joints of brick masonry is different from and the one in the $y$ direction $\left(E_{y}\right)$, which is perpendicular to the bed joints. In case of plane stress in an anisotropic material, $E_{x} v_{y x}=$ $E_{y} v_{x y}$ where $v_{x y}$ and $v_{y x}$ are Poisson's ratios in the $\mathrm{xy}$ and $\mathrm{yx}$ plane, respectively.In order to model the surrounding frame author used the same constitutive relation that is used for the modeling of masonry material giving the same value for the modulus of elasticity in the $\mathrm{x}$ and $\mathrm{y}$ directions. The complicated behavior of the infilled plane frames under lateral load similar to an earthquake load was modelled by using a criterion for the frame-infill separation. The evolution of the natural response of composite structures subjected to seismic lateral loads was descirbed as boundary condition problem by using this criterea. The accepted natural condition between the frame and the infill were either the contact or the seperation, i.e., infill panel cannot get into the surrounding frame. The infill finite elements were considered to be linked to the surrounding frame finite elements at two corner points at the ends of the compressed diagonal of the infill only as shown in Fig. (24a). Nodal forces and displacements of the deformed mesh are shown in Fig. (24b) and the stresses at the Gauss points of the elements were computed. A specific computer program for a 2D linear elastic analysis of infilled plane frames under lateral static loads was developed to implement the method.The problem was studied in the elastic region for monotonic loading. In addition, the estimated stiffness reduction ratio $(\lambda)$, which is defined as the ratio of stiffness with wall opening to the stiffness without a wall opening, was used for comparison with past data. Several frames with different configurations were analyzed under a $30 \mathrm{kN}$ horizontal loading with a similar uniform load distribution in the surrounding frame and infill wall surface Fig. (24c).

Parameters considered in the study were: presence (or not) of opening in the infill panel, percentage of opening (4, 9,16 , and $25 \%$ ), and position of opening to the compressed diagonal (three cases were considerd: case A - opening underneath the compressed diagonal, case B - opening over the compressed diagonal, and case $\mathrm{C}$ - opening above the compressed diagonal. Some of the opening positions studied are shown in Fig. (25a) where dots depict the contact/interaction areas between the infill masonry wall and the surrounding frame for different opening percentages. The variation of the $\lambda$ factor as a function of the opening percentage, i.e., opening area/infill wall area, for case B is also shown in Fig. (25b).Increase in the opening percentage lead to a decrease in the frame stiffness Fig. (25b). It can be seen that as the opening percentage goes beyong $50 \%, \lambda$ remains constant. It was observed that stiffness reduces when the opening is located over the diagonal because action of the compression diagonal of the infill wall is affected.The author proposes an improved method for the estimation of the width of the diagonal struts by using the values of 
Table 8. Comparison of Theoretical and Experimental Stiffness [4]

\begin{tabular}{|c|c|c|c|c|c|}
\hline \multirow{2}{*}{$\begin{array}{c}\text { Type and position of } \\
\text { opening }\end{array}$} & \multirow[b]{2}{*}{ Openings, in } & \multicolumn{2}{|c|}{ Frame without connectors } & \multicolumn{2}{|c|}{ Frame with connectors } \\
\hline & & $\begin{array}{l}\text { Experimental, } \\
\mathrm{Kgm} / \mathrm{cm} \times 10^{3}\end{array}$ & Theory, $\mathrm{Kgm} / \mathrm{cm} \times 10^{3}$ & $\begin{array}{c}\text { Experimental, } \\
\mathrm{Kgm} / \mathrm{cm}^{\prime} \times 10^{3}\end{array}$ & Theory, Kgm/cm $\times 10^{3}$ \\
\hline $\mathrm{O}-0$ & No opening & 20 & 18.2 & 33.4 & 39.2 \\
\hline O-1 & $6 \times 6$ & 23 & 17.8 & 30.8 & 34.5 \\
\hline $\mathrm{O}-2$ & $6 \times 6$ & 17.85 & 17.7 & 46.5 & 39.13 \\
\hline $\mathrm{O}-3$ & $6 \times 6$ & 15.4 & 17.35 & 36.4 & 34.5 \\
\hline $\mathrm{O}-4$ & $6 \times 6$ & 3.12 & 7.85 & 12.2 & 35 \\
\hline $\mathrm{O}-\mathrm{C}$ & $4.8 \times 4.8$ & 16 & 15.2 & 30.8 & 35.4 \\
\hline O-5 & $6 \times 6$ & 23.2 & 17.6 & 33 & 38.9 \\
\hline O-9 & $6 \times 6$ & 16.1 & 17.4 & 37.8 & 36.8 \\
\hline O-5.9 & $12 \times 6$ & - & 15.3 & - & 35.9 \\
\hline
\end{tabular}

stiffness reduction factors obatined for various cases. According to this new method equivalent width is given by a simplified formula:

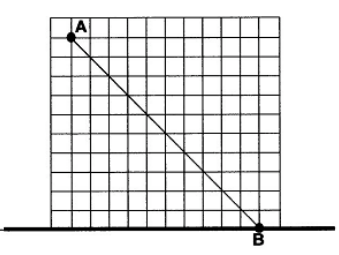

(a)

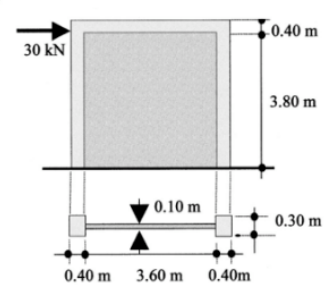

(c)

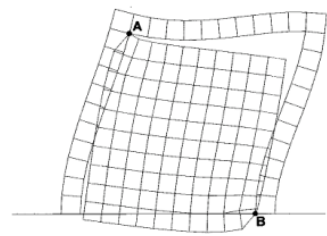

(b)
Fig. (24). (a) The generated mesh showing the points of link A and $\mathrm{B}$, (b) the first derived mesh showing deformations, and (c) single story single frame infilled frame considered for the study [23].

$(\mathrm{w} / \mathrm{d})=0.175 \lambda(\lambda \mathrm{h})^{-0.04} ; \lambda h=h \sqrt[4]{\frac{E_{b} t \sin 2 \theta}{4 E_{s} I h}}$

Where $E_{b}, t$, and $h$ are elastic modulus, thickness, and height of infill, respectively, $E_{s}$ and $I$ areYoung's modulus and moment of inertia of the surrounding frame member, and $\theta$ is angle between the infill diagonal and the horizontal. The variation of contact length for different opening positions were also studied, and it was obserevd that the contact length between the infill and the beam depends on the opening position. Increase in the opening size lead to decrease in the contact length for cases $\mathrm{B}$ and $\mathrm{C}$, whereas an increase was observed in case A. Contact length between infill and windward column was also influenced by position of the opening. Increase in the opening size resulted in decrease of contact length in case $\mathrm{A}$ and $\mathrm{B}$, but increase in case $\mathrm{C}$.

Lateral stiffness of 2-D bracing systems with openings was presented by Papia [24]. Panels stiffened by surrounding frames and/or by inner frames along the boundary of the openings were also considered. Analytical expressions for panels without stiffening frames have been deduced based on numerical results obtained by FEM. Centroid of the openings was kept on the vertical symmetry axis of panel, and value of $h / l$ was kept equal to $H / L$ Fig. (26a). To understand variation of stiffness on position of the opening along the height, a parameter $c /(h-H)$ was also considered in the study. Numerical results showed that when $H / L$ and $l / L$ were kept constant, the maximum stiffness was obtained when $c /(h-H)$ was equal to zero.

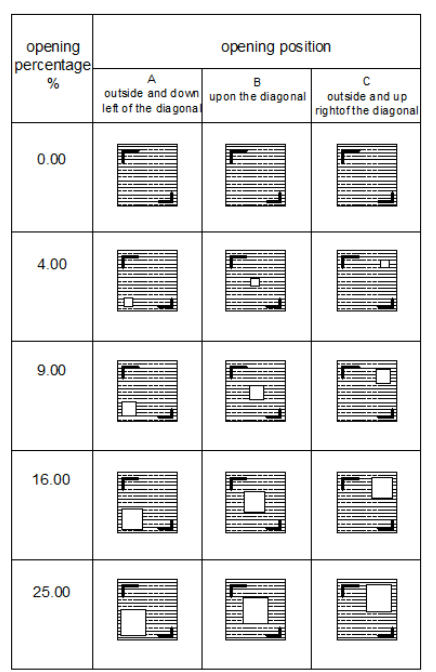

(a)

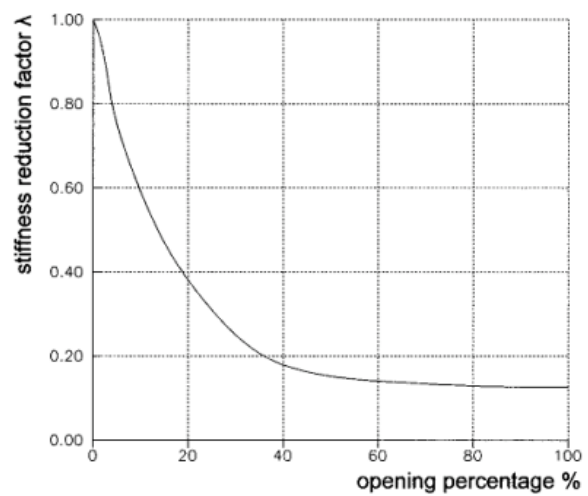

(b)

Fig. (25). (a) Contact are as between infill wall and surrounding frame for different opening percentages, and (b) stiffness reduction factor $\lambda$ of infilled frame in relation to opening $\%$ for case B [23]. 


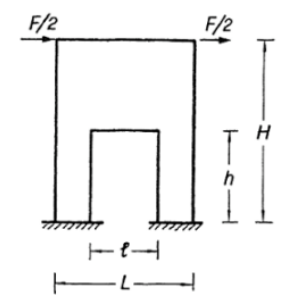

(a)

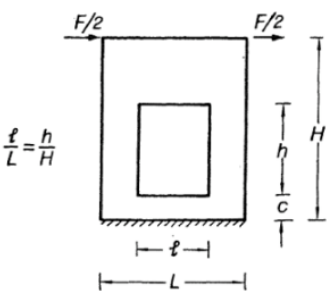

(b)

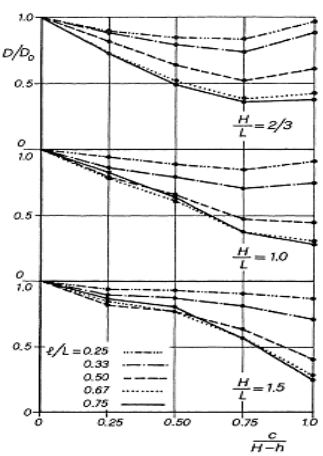

(c)

Fig. (26). (a), (b) model of panels with openings, and (c) stiffness ratios versus opening position [24].

Following observations relating to $/ / L$ ratio and influence on stiffness $\left(D_{0}\right)$ were made in the case of panels with same configuration as the one in Fig. (26a). It was observed that for $0 \leq l / L \leq 0.25$ there was insignificant influence of openings on stiffness. Similarly, for $0.25 \leq l / L \leq 2 / 3$ stiffness decreases linearly as $l / L$ increases, and for $l / L>2 / 3$ stiffness decreases exponentially as $l / L$ increases. In case of panels with varying position of the opening along the height as in Fig. (26b), the stiffness $(D)$ varied differently in relation to the parameter $H / L$, when $l / L$ was kept constant. The ratio between the stiffness $D$ and $D_{0}$ was examined for three values of $H / L$ Fig. (26c).It was evident that the position of opening has a major influence on the stiffness of the panel; stiffness reduces as the opening moves towards the top, until the value $c /(h-H)$ reached 75 . Influence of opening position becomes more significant as the ratio $l / L$ increases, up to a limiting value of 0.6 to 0.7 , beyond which the curves are almost coincident. The stiffness of frames without any opening in the infill, and stiffness of panels with opening, but no surrounding frames, was estimated. The stiffness of the frames with surrounding frame and openings in panel was evaluated by adding the stiffness of the two panel schemes mentioned above, whose stiffness were estimated already. The study supports the usage of panels with frames surrounding the openings to withstand the effects of seismic forces.

Discontinuous deformation method (DDA) method was used by Chiou et al. [16] to numerically model three RC frames: bare, partially infilled, and fully infilled. The prototype of DDA could efficiently analyze the discontinuous structural behavior, whereas it was less efficient for continuous structure. A modified DDA method was used by authors where in a concept of artificial joints was included in the study. In DDA, variables are displacements and the equilibrium equations are solved in the same manner as FEM. Blocks are independent and connection exists only when the blocks are in contact. This method incorporated complete kinematics that fulfills no interpenetration and no tension between blocks at any time. Interactions between blocks were simulated by contact springs. The failure of mortar is mainly in two modes - tension and shear; mixed mode of failure was neglected. Characteristics of the tension failure are similar to the condition of no tension between blocks in DDA, and shear failure was considered similar to the friction between the blocks. Bricks are simulated by sub-blocks connected by contact springs. Stiffness of spring is directly proportional to strength of mortar.Failure criteria of mortar are given as:1) tensile failure: tensile strength of mortar is assumed to be $\sigma_{t}$, where tensile normal stress of mortar is $\sigma$. Tensile failure criterion of mortar is written as $\sigma \geq \sigma_{t} ; 2$ )shear failure: shear failure of mortar is assumed to follow the Mohr-Coulomb criterion. Shear strength of mortar $\tau_{f}$ is written as $\tau_{f}=\tau_{0}+\sigma_{n} \tan \varphi$, where $\tau_{0}$ is cohesion of mortar, $\varphi$ is internal friction angle, and $\sigma_{n}$ is normal stress. Short column effect is evident from principal stress distribution of partially filled frame Fig. (27). DDA method predicted higher displacements compared to experimental study in case of partially infilled frame. This can be attributed to the fact that no window frame was considered in the numerical modeling.Comparing results of the analytical study and experiments, authors concluded that DDA method was a reliable method for analysis of RC frames.

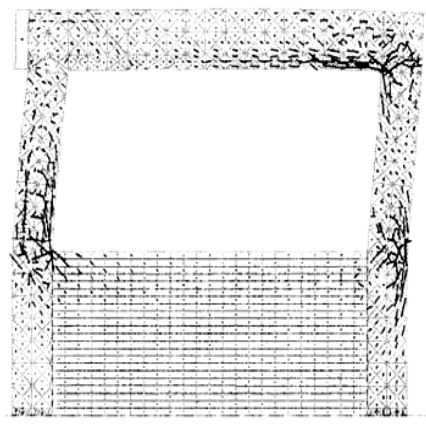

Fig. (27). Principal stress distribution using DDA method [16].

For infilled frames with or without opening, Liauw [25] used an approximate method of analysis based on the concept of equivalent frame. Experimental results on stiffness of two elastic models having various sizes of opening in the infill were compared with the analytical results. Results showed good agreement when the central opening was more than half of the full infill area. Author divides the methods of analysis into two groups: an approximate approach using analogous frame method, and a more accurate approach using stress function method or finite element method. The first approach is based on the concepts of replacing the infill by an equivalent diagonal strut in each frame to form an analogous frame. This method is incapable of treating an infilled frame with an opening in the infill. The second approach requires a computer even for a simple infilled frame. The obtained values from analytical model were not compared to a steel or concrete frame with infill,instead elastic models were tested.The testing of elastic models could not simulate the actual scenario because stiffness degradation and energy dissipation could not be obtained in such models.

Liauw and Lee [26] used equivalent frame method to analyze some models and compare the results with the experimental values. Modular ratios of two different materials were used to transform the actual members into equivalent 
Table 9. Strength Prediction Equivalent Frame Method [26]

\begin{tabular}{|c|c|c|c|c|c|}
\hline \multirow{3}{*}{ Model } & \multirow{3}{*}{$\begin{array}{c}\begin{array}{c}\text { Experimental ulti- } \\
\text { mate load, } \mathrm{kN}\end{array} \\
\mathrm{A} \\
\end{array}$} & \multicolumn{2}{|c|}{ Predicted ultimate load, kN } & \multirow{3}{*}{ B/A, \% } & \multirow{3}{*}{ C/A, \% } \\
\hline & & With shear connection & Without shear connection & & \\
\hline & & B & $\mathbf{C}$ & & \\
\hline AS1 & 133.5 & 114.6 & 121.6 & 86 & 91 \\
\hline AS2 & 100.6 & 59.7 & 96.7 & 89 & 96 \\
\hline AS3 & 99.6 & 78.2 & 83.7 & 79 & 84 \\
\hline AS4 & 81.7 & 72.8 & 78.7 & 89 & 96 \\
\hline BS2 & 114.6 & 99.6 & 117.6 & 87 & 103 \\
\hline BS3 & 102.6 & 100.6 & 103.6 & 98 & 101 \\
\hline BS4 & 95.7 & 94.7 & 97.6 & 98 & 103 \\
\hline CS1 & 174.4 & 149.5 & 144.5 & 86 & 83 \\
\hline $\mathrm{CS} 2$ & 153.4 & 138.5 & 136.5 & 90 & 89 \\
\hline $\mathrm{CS} 3$ & 122.6 & 111.6 & 109.6 & 91 & 89 \\
\hline $\mathrm{CS} 4$ & 101.6 & 100.6 & 99.6 & 99 & 98 \\
\hline
\end{tabular}

sections. The properties of the equivalent frame are same as those of the actual frame. From the centroidal axis of the infilled frame, the dimensional parameters of equivalent frames are obtained [5]. Since the transformed sections of the equivalent frame normally consist of deep beams and wide columns, shear strain energy was taken into account. These considerations affected the stiffness and strength of the equivalent frame to a varying degree. Having taken into account some or all of the considerations, the equivalent frame was analyzed by using usual structural analysis methods.

Two analytical models (equivalent diagonal strut method and equivalent frame method) were presented by authors and the analytical models covered infill frames without connectors and with connectors. When connection was used, the separation along the parts of the interface occurred when subjected to moderate lateral load. In case of equivalent diagonal strut method, the strain energy method was used to establish the properties of equivalent diagonal struts. When the connectors are provided, the interaction produced by the infills acting compositely with the frames invalidates the assumptions and the theory of the equivalent diagonal strut analogy. In such cases the equivalent frame method, as mentioned earlier in the section was used. Strength predictions done by equivalent frame method and by equivalent diagonal strut method are shown in Tables $\mathbf{9}$ and $\mathbf{1 0}$.

Mohebkhah et al. [27] proposed two kinds of numerical modeling strategies to simulate the in-plane nonlinear static behavior of infilled frames with openings The complexity associated with nonlinear numerical modeling of masonryinfilled frames is attributed to the existence of joints as the major source of weakness and material nonlinearities as well as the infill-frame interaction. The authors present here a two dimensional numerical model using the specialized discrete element software UDEC (Universal Distinct Element Code) for the nonlinear static analysis of infilled steel frames with openings. Interaction between frame and infill panel significantly increases the lateral stiffness of infilled frame and drastically alters the expected dynamic response of the structure. Numerical modeling strategies of infilled frames are divided into two distinct categories: micro-modeling, and macro-modeling. Numerical method such as finite element method or discrete element method is used to establish details of both surrounding frame and the infill wall component in micro-modeling of masonry infilled frames. In macromodeling method, the masonry infill wall is replaced by an equivalent pin-jointed diagonal strut requiring less computational time and effort. The equivalent width of the strut depends on the relative infill-frame stiffness. In the DEM model, the masonry infill panel is modeled at a semi-detailed level (micro-modeling strategy) with joints modeled as an interface with zero thickness. In this approach, fictitious expanded block dimensions are used that are of the same size as the original dimensions plus the real joint thickness. It follows that the elastic properties of the expanded block and the interface joint must be adjusted to yield correct results. The interface stiffness is deduced from the stiffness of the real joint as follows:

$$
\begin{aligned}
& k_{n}=\frac{E_{b} E_{m}}{h_{m}\left(E_{b}-E_{m}\right)} \\
& k_{s}=\frac{G_{b} G_{m}}{h_{m}\left(G_{b}-G_{m}\right)}
\end{aligned}
$$

Where $E_{b}$ and $E_{m}$ are Young's modulus, $G_{b}$ and $G_{m}$ are shear modulus, respectively, for block and $h_{m}$ is the actual thickness of the mortar. The accuracy of this methodology has been verified using some detailed discontinuum finite element analysis by some other researchers. The inelastic, isotropic model was used for the behavior of the blocks, which were considered fully deformable, thus allowing deformation to occur both in the blocks and joints. A better simulation of crack propagation and sliding in the joints was obtained using this model, which was based on the UDEC Mohr-Coulomb model with tension cut-off in conjunction with non-associated shear and associated tension flow rules. Since the steel frame components in the model were expected to behave inelastically at ultimate state of loading, a Von-Mises material model was chosen to represent the steel frame behavior. As Von-Mises criterion was not available in 
Table 10. Strength Prediction by Equivalent Diagonal Strut Method [26]

\begin{tabular}{|c|c|c|c|c|c|}
\hline \multirow{3}{*}{ Model } & \multirow[t]{2}{*}{ Experimental ultimate load, $\mathrm{kN}$} & \multicolumn{2}{|c|}{ Predicted ultimate load, kN } & \multirow[t]{3}{*}{$\mathrm{B} / \mathrm{A}, \%$} & \multirow[t]{3}{*}{$\mathrm{C} / \mathrm{A}, \%$} \\
\hline & & $C_{1}=0$ & $C_{1}=h_{1} / 2$ & & \\
\hline & $\mathbf{A}$ & B & $\mathbf{C}$ & & \\
\hline $\mathrm{AO} 1$ & 97.6 & 71.7 & - & 73 & - \\
\hline $\mathrm{AO} 2$ & 53.8 & 30.9 & 32.9 & 57 & 61 \\
\hline $\mathrm{AO} 3$ & 58.8 & 31.9 & 32.9 & 54 & 56 \\
\hline $\mathrm{AO} 4$ & 55.8 & 29.9 & 31.9 & 54 & 57 \\
\hline $\mathrm{CO} 1$ & 102.6 & 85.7 & - & 84 & - \\
\hline $\mathrm{CO} 2$ & 63.8 & 41.8 & 43.8 & 66 & 69 \\
\hline $\mathrm{CO} 3$ & 62.8 & 42.8 & 45.8 & 68 & 73 \\
\hline $\mathrm{CO} 4$ & 59.8 & 41.8 & 46.8 & 70 & 78 \\
\hline
\end{tabular}

UDEC, the Drucker-Prager criterion was degenerated into the Von-Mises criterion for $\varphi=0$. Although the steel frame components were made up of steel I-sections, they were modeled as solid blocks of steel with equivalent elastic and inelastic mechanical properties and sequential analysis was carried out. A displacement controlled method was used to obtain the collapse load. The developed discrete element model was employed to simulate the in-plane behavior of a concrete masonry-infilled steel frames tested at the University of New Brunswick by Dawe and Seah [11].

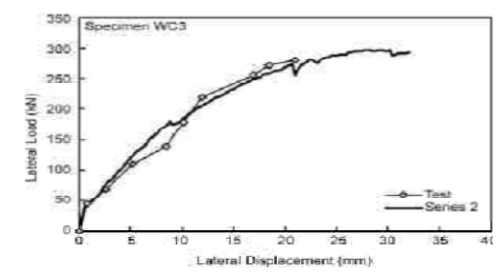

(a)

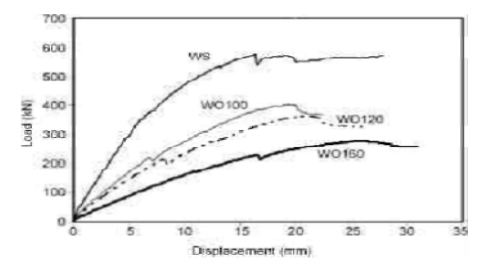

(b)

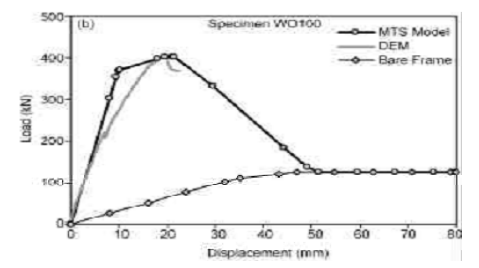

(c)

Fig. (28). (a) Experimental and numerical lateral load-displacement diagrams for specimen WC3, (b) lateral load-displacement diagrams for all the models using DEM, and (c) load-displacement relations for specimenWO100 [27].

Among the 28 large-scale specimens tested under racking load in the program, specimen WC3 was chosen.The specimen was a single panel $3,600 \mathrm{~mm}$ long by $2,800 \mathrm{~mm}$ high concrete masonry-infilled steel frame with $0.8 \times 2.2 \mathrm{~m}$ central door opening. Infill panel consisted of $200 \times 200 \times 400 \mathrm{~mm}$ concrete blocks placed in running bond.Up to a deformation at which the failure mechanism is formed, load-displacement diagram from the experimented specimen, as well as the numerical results are shown in Fig. (28a). The obtained results show only $4 \%$ error suggesting that DEM has capability to model frames with openings in the infill panel.

A parametric study was conducted using the DEM micromodel that was developed to investigate the effect of the size of central window openings on the lateral strength and stiffness of infilled steel frames. The effect of opening size on the lateral capacity of the infilled frames was studied for various values of a parameter denoted by $\alpha$ that was defined as the percentage of relative ratio of the opening area to the solid infill panel area. The infilled steel frame analyzed earlier to compare with experimental results was considered with the same properties and a central window opening of different sizes. The models which the analyzed models were WS, WO100, WO120, and WO160. The symbols WS and $\mathrm{WO}_{\mathrm{x}}$ stand for the reference solid infilled frame and infilled frame with a central square window opening of " $x$ " dimensions in centimeters, respectively. Fig. (28b) illustrates the comparison between the numerical load-displacement diagrams of all the above-mentioned models up to a deformation at which the failure mechanism is formed. It is obvious that due to the presence of openings in infill panels, the lateral strength and stiffness of infilled frames is reduced. The results were not validated using experimental study.

El-Dakhakhni et al. [28] proposed an efficient macromodel for the pushover analysis of the infilled frames up to failure. The infill panel was replaced by three struts; one diagonal and two off-diagonal, connecting the two loaded corners and the points of maximum moments in the beams and the columns, respectively. The advantage of using this three-strut model rather than the single diagonal strut was that in this model the internal forces (i.e., shear forces and bending moments) in the frame members could be estimated. However, this three-strut model was not applicable to the analysis of infilled frames with openings. Mohebkhah et al. [27] modified the three-strut model to simulate the nonlinear static behavior of masonry-infilled frames with openings. In this regard pushover analysis was used using nonlinear SAP2000 program to generate the load-displacement relations of the specimens. The load-displacement relations for the bare and the infilled frames are shown in Fig. (28c) along 
Table 11. Details of the Specimens Analysed [29]

\begin{tabular}{|c|c|c|c|}
\hline Specimen & Description & $\begin{array}{c}\text { Initial major } \\
\text { cracking load(kN) }\end{array}$ & $\begin{array}{c}\text { Maximum } \\
\text { lateral load(kN) }\end{array}$ \\
\hline \hline WC7 & Solid masonry-infilled frame & 310 & 534 \\
\hline WC3 & Same as WC7 but with $0.8 \times 2.2 \mathrm{~m}$ central door opening & 90 & 285 \\
\hline WC5 & Same as WC3 but with openingoffsets $600 \mathrm{~mm}$ from centertowards the loaded \\
side & 645 \\
\hline WC6 & Same as WC3 but with openingoffsets $600 \mathrm{~mm}$ from center awayfrom the loaded \\
side & 67 & 365 \\
\hline
\end{tabular}

with discrete element results for comparison. As it can be seen, the modified three strut model (MTS) can predict both stiffness and ultimate load capacity of the masonry-infilled frames with openings up to failure. The maximum error between DEM and MTS model ultimate loads is about 5\%. However, the proposed model did not take into account the different opening locations in the infill panel. Also, the model was not capable of predicting the ductility of such frames with openings correctly.

As an extension to the above mentioned study, a twodimensional numerical model using the specialized discrete element method software UDEC was also developed by Mohebkhah et al. [29]. The model was used for the nonlinear static analysis of masonry-infilled steel frames with openings. Authors state that continuum based method give satisfactory results but fail to provide a practical analysis for masonry structures. In the DEM, large displacements and rotations between blocks, including sliding between blocks, the opening of the cracks and even the complete detachment of the blocks and automatic detection of new contacts are allowed. UDEC treats discontinuities as boundary conditions between blocks. It is assumed that the blocks are connected by normal and shear elastic springs to model the mechanical interaction between blocks. DEM uses mechanical damping to solve both static and dynamic solutions. The modeling in this study was employed to study the nonlinear lateral load behaviour of some concrete masonry infilled steel plates tested by Dawe and Seah [11]. Among the 28 large scale sample specimens tested by authors, specimens WC3, WC5, WC6 and WC7 were chosen for modeling. The details of all the specimens are provided in Table 11.Elastic parameters were calculated from Equations (4) and (5). A strainhardening/softening material model was used to build the concrete blocks. Strain-softening model for the blocks is described by two parameters $c$ and $\varphi$. Following equations were used to find the angle of internal friction and cohesion of concrete in terms of concrete compressive strength $\left(f_{c}^{\prime}\right)$ :

$\phi^{0}=0.145 f^{\prime}{ }_{c}(M P a)+49.71$

$c(M P a)=0.1065 f_{c}^{\prime}(M P a)+0.531$

For the joints, simulating the characteristics of mortar, Mohr-Coulomb slip model was employed. Fig. (29a) illustrates the comparison between load-displacement diagram of experimental specimen WC3 and that of the numerical analysis upto a deformation till failure mechanism is formed.
Local peaks in the curve correspond to the state at which a new joint crack occurred or plastic behavior took place in the blocks. The agreement between experimental and numerical responses was reported to be satisfactory with a maximum error of $20 \%$ for specimen WC5 and average error of $1 \%$ Table 12.

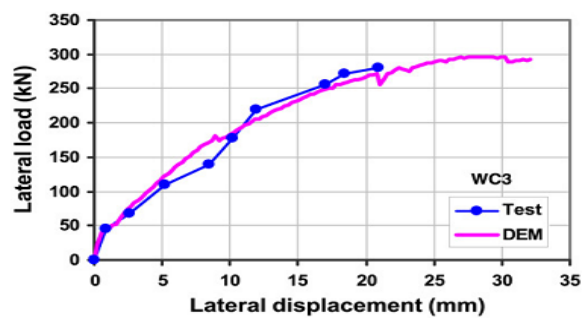

(a)

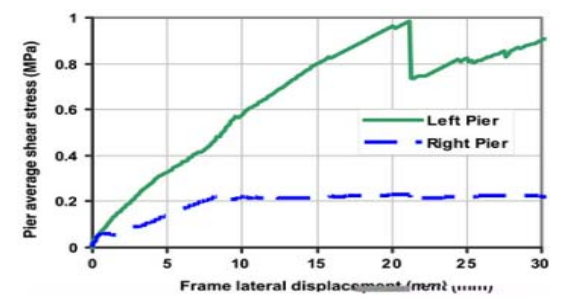

(b)

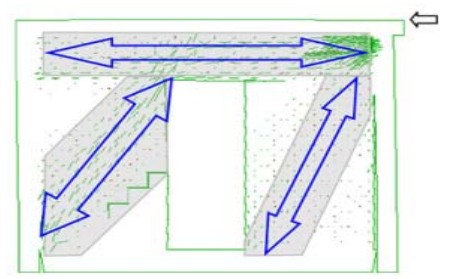

(c)

Fig. (29). Specimen WC3: (a) Load displacement relation, (b) shear stress in piers versus lateral displacement in frame obtained from numerical analysis, and (c) principal stress tensors for infill [29].

Fig. (29b) shows the variation of average shear stress in piers at top horizontal section versus lateral displacement of the frame. It can be seen that, up to lateral displacement of $0.5 \mathrm{~mm}$, both piers contribute to the lateral-resisting system equally. From this point, the value of right pier shear stress increases gradually indicating the horizontal movement of the pier. Fig. (29c) shows a representation of the principal stress tensors for the WC3 model at ultimate capacity. In this 
Table 12. Comparison of Experimental and Numerical Collapse Loads [29]

\begin{tabular}{|c|c|c|c|}
\hline Specimen & Experimental (kN) & Numerical (kN) & Ratio (Num./Exp.) \\
\hline \hline WC7 & 534 & 501 & 0.94 \\
\hline WC3 & 285 & 297 & 1.04 \\
\hline WC5 & 245 & 295 & 1.20 \\
\hline WC6 & 365 & 368 & 1.01 \\
\hline
\end{tabular}

figure, principal stress directions show the activated compressive parts orientation of the infill panel subjected to lateral loading. Due to the presence of opening, the infill panel is forced to act as three distinct parts as shown in Fig. (29c) with shaded areas including one horizontal and two activated inclined compressive component. As it is in common practice, the opening is bounded by an internal frame to restrain the blocks from falling into the opening; the effect of such frames on the lateral load capacity of masonry-infilled frames with openings was also investigated in model WC3. The door frame members were assumed to be rectangular in cross-section (box steel section $120 \times 60 \mathrm{~mm}$ ) with rigid corner connections and the door frame was assumed to be a moment-resisting frame. It was seen that due to the presence of support frame around the opening, both stiffness and lateral load carrying capacity of the specimen increased because the use of door frame enhanced the behavior of right pier. The study with door frame was of much practical significance as it is common practice to provide frames around the openings. Parameters like opening sizes, aspect ratio were not explored in the study.

In order to examine the effect of central openings of different sizes on the initial lateral stiffness of infilled frames, Mondal and Jain [30] analysed single bay single story, singlebay two story, and single bay three story infilled frames, and proposed a reduction factor for effective width of diagonal strut over that of the solid RC infilled frame to calculate its initial lateral stiffness. Lateral load-deflection curve of an infilled frame was divided into three parts, such that, in the initial part there is lack of fit between frame and infill, second part is approximately linear and reflects the interaction between frame and infill, and in the third part stiffness reduction takes place. Stiffness of the second part was considered assuming that this is achieved well before a load level of $10 \%$ of the lateral strength of infilled frame. Therefore, the initial stiffness was defined as the stiffness level corresponding to $10 \%$ of the lateral strength of infilled frame. Past experimental results of seven different specimens published in the literature were used to verify the model. The single bay single story infilled frame considered is shown in Fig. (30a). Central openings of widths $500 \mathrm{~mm}, 1000 \mathrm{~mm}, 1500$ $\mathrm{mm}, 2000 \mathrm{~mm}, 2500 \mathrm{~mm}$ and $3000 \mathrm{~mm}$ were considered. For each of these widths of opening, the considered heights of openings were $500 \mathrm{~mm}, 1000 \mathrm{~mm}, 1500 \mathrm{~mm}, 2000 \mathrm{~mm}$ and $3000 \mathrm{~mm}$.

In the finite element method, standard two-noded frame elements with two translational degrees of freedom and one rotational degree of freedom at each node were used to model the frame elements. The infills were idealized by fournoded plane stress rectangular or square area elements with two translational degrees of freedom at each node Fig. (30b). Interface of the infill and frame were modeled using linear springs incapable of taking any tension. Experimental results available in the published literature for two RC bare frames, three RC infilled frames without any opening, and two RC infilled frames with central window openings were used to calibrate the FE model.

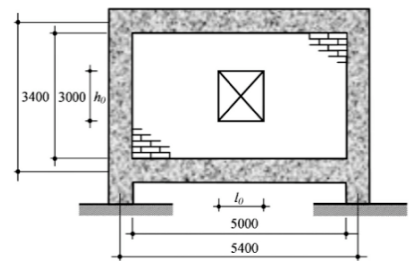

(a)
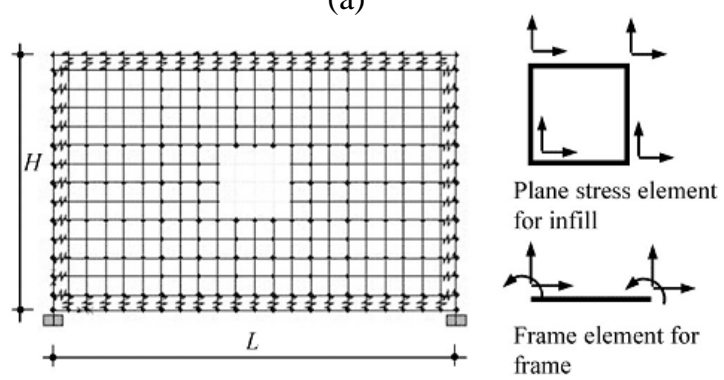

(b)

Fig. (30). (a) Dimensions (mm) of single-bay, single-story infilled frame with symmetric central opening, and (b) finite element modeling of single-bay, single-story infilled frame with opening [30].

The influence of the following four factors namely, flexural rigidity of components, modulus of elasticity of masonry, rigidity of beam-column junction, and separation between frame and infill were examined in the analysis. Cracked flexural rigidity of components was taken as $50 \%$ of uncracked section in beam and in tension column and $70 \%$ of uncracked section in compression column. According to authors, the assumption of centerline dimensions is often inaccurate; therefore,finite size of the joint was modelled through the use of rigid-end-offsets option. Three types of rigidity of the beam-column joints namely, rigid, semi rigid, and flexible were used to investigate the effect of finite size of the joint Fig. (31). Two types of frame-infill interface were considered: separation between frame and infill was not allowed in the first type, while in the second type, separation between frame and infill at the non-loaded diagonal was allowed. To account for this, linear springs were used as interface elements. Results of the bare frames showed that using the uncracked flexural rigidity of components results in up to $120 \%$ error (average $70 \%$ ), and models with flexible beamcolumn joints exhibited up to $50 \%$ error with an average 

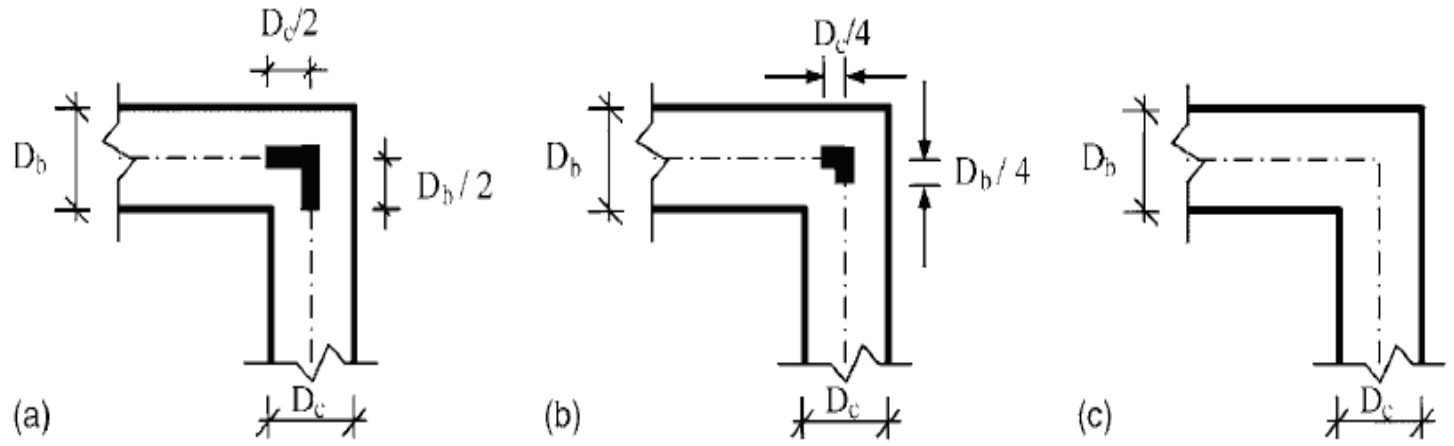

Fig. (31). Modelling of beam-column joint-end-offsets: rigid end-offset, semi rigid end offset, and flexible end-offset [30].

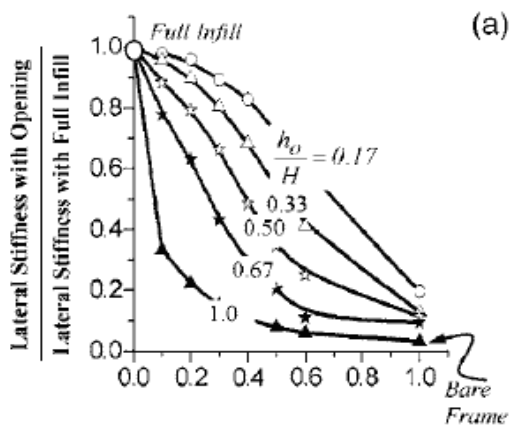

(a)

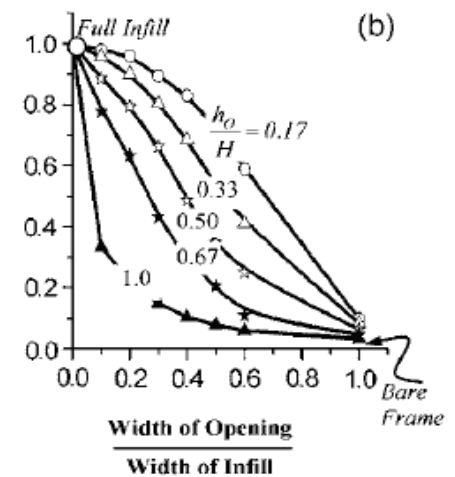

(b)

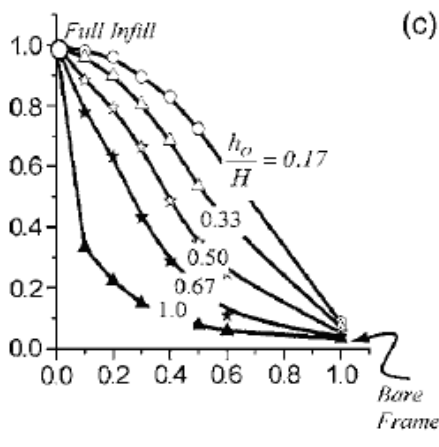

(c)

Fig. (32). Effect of opening size on lateral stiffness of infilled frame determined by finite element analysis of: (a) single-story, (b) two-story, and (c) three-storyframes [30].

error of $26 \%$. On the other hand, the models involving the combination of cracked flexural rigidity of components and rigid and semi rigid beam-column joints resulted in maximum $20 \%$ error with an average error of $10 \%$. Analysis of infilled frames indicated that elastic modulus of masonry based on empirical formula by Drysdale et al. [31] yields reasonable estimate of the initial lateral stiffness. Complete contact between the frame and the infill resulted in large error $(\sim 300 \%)$ in initial lateral stiffness. Therefore, separation between frame and infill at the non-loaded diagonal proved to be a significant factor.

Initial lateral stiffness determined by analysis of frames is shown in Fig. (32). Width and height of opening is normalized with respect to width and height of infill, respectively, and the lateral stiffness of infilled frames is normalized with respect to that of the fully infilled frames. Presence of openings significantly reduced the initial lateral stiffness of infilled frames. A sharp decrease in initial lateral stiffness is observed for the openings extended to full height or full width of the infill. In case of two similar rectangular frames with equal areas of openings, the frame having larger width of opening exhibits more initial lateral stiffness. As the height of opening increases the panel is divided into two subpanels which increase the possibility of formation of multistrut as shown in Fig. (33). For the same area of opening if the dimensions of opening vary, the difference in initial stiffness is less than $10 \%$. Hence, except in extreme cases, area of opening (and not the height-to-width ratio of open- ing) governs the lateral stiffness of infilled frame. Therefore, the reduction factor proposed in this article does not depend upon the height to width ratio of the opening. The effect of strut-width on lateral stiffness of the infilled frames is shown in Figs. (33a, 33b, and 33c). It is seen that the lateral stiffness of infilled frames increases almost linearly with increasein strut-width.

Effect of opening on the lateral stiffness of the infilled frame was represented by a diagonal strut of reduced width. This reduction in strut-width was denoted by a factor $w$, which is defined as ratio of reduced strut-width to strutwidth corresponding to fully infilled frame, and was proposed as:

Strut width reduction factor $(w)=\frac{\text { Strut width of Infilled Frame with Opening }\left(w_{d o)}\right.}{\text { Strut width of Fully Infilled Frame }\left(w_{d s}\right)}$

A fiber based finite element program, of a double strut non-linear cyclic model for unreinforced masonry panels, was implemented by Smyrou et al. [32]. Authors divided the modeling techniques in this area into two main groups: local or micro models, and simplified or macro models. The model featured the double strut approach as shown in Fig. (34a). Four struts and two shear springs represent each infill Fig. (34b). Each diagonal direction featured two parallel struts to account for compression/tension forces and deformations across two opposite diagonal corners and a shear spring to account for bed-joint resistance and sliding. This latter spring, the presence of which reflects the importance of 
shear formation/strength in the response of unreinforced masonry panels, acts solely across the diagonal that is in compression, hence its "activation" depends on the deformation of the panel. As can be observed in Fig. (34b), four internal nodes are employed to account for the actual points of contact between the frame and the infill panel (i.e., to account for the width and height of the columns and beams, respectively), whilst four dummy nodes (i.e., a second strut) are introduced with the objective of accounting for the contact length/width between the frame elements and infill panel. In other words, the purpose of using the double strut approach is to consider the moments and shear forces that are normally introduced in the columns as a result of the eccentricity with which infill panels compress their adjacent frame members.

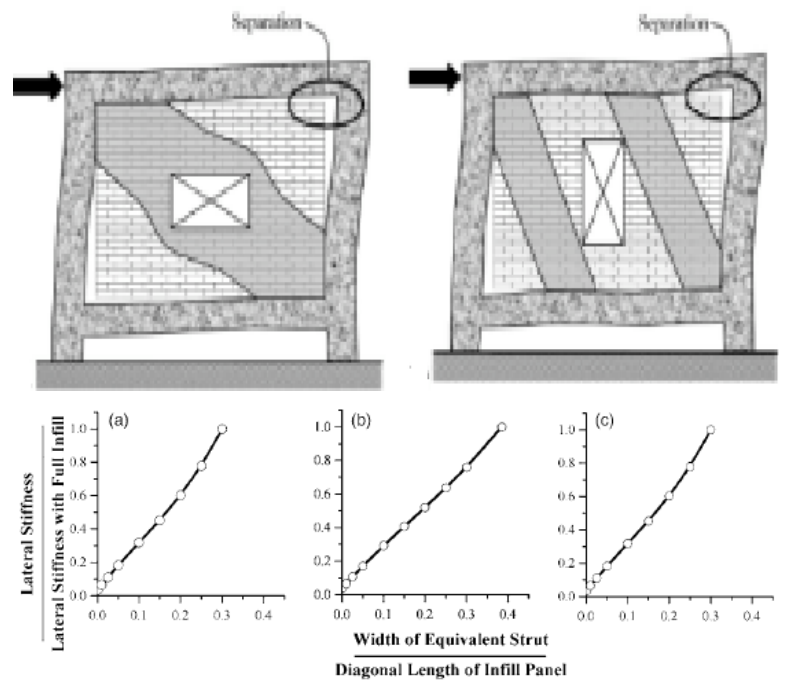

Fig. (33). Formation of diagonal strut andeffect of width of equivalent diagonal strut determined by single equivalent diagonal strut analysis on lateral stiffness of: (a) single-story, (b) two-story, and (c) three-story frames [30].

The obtained displacements and forces in the dummy nodes are transferred to the adjacent internal nodes. The model does not have the capacity of modeling possible plastic hinges in the columns. For comparison results available in the literature in which researchers carried out pseudo-static tests in two single-bay infilled frames constructed to a reduced scale were used [33]. Openings in the infill panel were taken into account by reducing the value of $A l$ (the compression/tension strut cross-section) by a value that ranged between 30 and $50 \%$, as a function of the window and door. It is certainly recognized that some fine-tuning and tweaking of the numerical model was carried out, in order to define such openings-driven reductions. The results obtained with current implementation of the model, which was carried out independently and using different software with respect to the original attempts, seem to be reasonably satisfactory Fig. (35).

Dynamic characteristics of multistoried masonry infilled buildings were studied by Thiruvengadam [34]. Natural frequency, free vibration modes and damping, are three basic dynamic characteristics required to be known for evaluating dynamic response of structure for a given dynamic load. Author presents three approximate models to evaluate the first two parameters: a model based on a multiple strut anal- ogy, a shear flexure cantilever model, and an equivalent frame model. For comparing the results, available experimental results and finite element solutions were taken as basis. The effect of separation on the free vibration response was also discussed and constructional procedures were suggested to avoid separations.

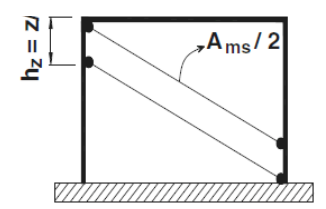

(a)
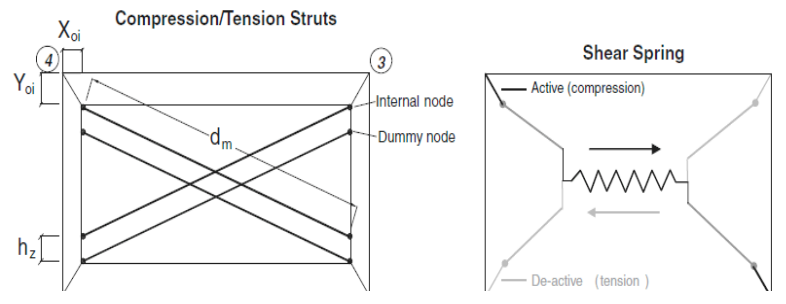

(b)

Fig. (34). (a) Double strut model and (b) implemented infill panel model [32].

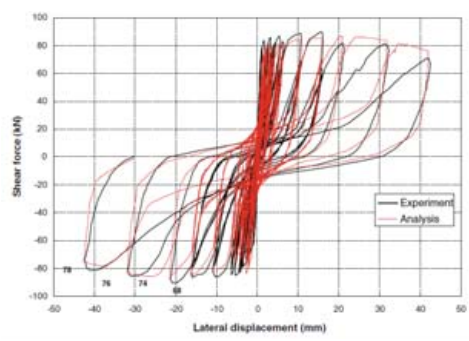

(a)

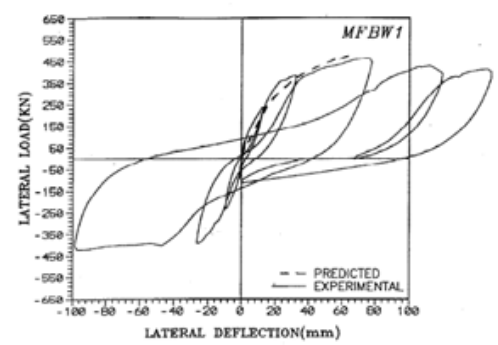

(b)

Fig. (35). (a) Experimental and numerical response curves for frame, and (b) P- $\Delta$ curve for confined brick wall with opening [32].

According to the author single equivalent strut approach is satisfactory when the frame infill contact is confined around the diagonally opposite corners. The reciprocal stiffening effect is used to derive the composite stiffness of the structure when the infill bears against a certain finite length of the frame members. The model proposed by the author consists of a moment resisting frame with a number of pin jointed diagonal and vertical struts as shown in Fig. (36). Vertical strut was modeled by dividing the infill into a number of vertical strips and each strip was replaced by truss elements of corresponding stiffness. The end half strips adjacent to the columns are converted into an equivalent area of frame material and added to the column cross sectional area. 
The infill panel was discretized into a grid of shear panels and each such panel, considered under the state of pure shear was replaced by two diagonals, one acting in compression and the other in tension, to model diagonal struts. All the shear panels were identical, thus all the struts had same equivalent area. The number of struts could be increased by increasing the fineness of the shear grid. The thickness and modulus of elasticity of the struts were the same as that of the original infill. Lateral stiffness of an individual shear panel was given by:

$\frac{S}{\Delta}=\frac{G a t}{b}$

where, $G$ and $t$ were the shear modulus and thickness of the infills. This shear stiffness was modeled by two compression/tension pin jointed diagonals of an equivalent truss system having rigid peripheral members. For the lateral displacement $\Delta$, the axial strain in each strut was given by:

$\frac{\Delta}{a} \cos ^{2} \theta$

The lateral component of the axial force induced in each strut was given by:

$A d E_{t} \frac{\Delta}{a} \cos ^{3} \theta$

where, $A d$ is the area of the strut and $E_{t}$ the modulus of elasticity of the infill material. The total lateral force required to cause the displacement $\Delta$ is given by:

$\frac{2 A d E_{t} \cos ^{3} \theta}{a} \Delta$

Hence the lateral stiffness of the equivalent trusses can be calculated as:

$\frac{2 A d E_{t} \cos ^{3} \theta}{a}$

Equating equations (10) and (13), and substituting $\operatorname{Gas} E_{t} / 2(1+v)$, area of each diagonal strut was obtained as:

$$
A d=\frac{a^{2} t}{4 b(1+v) \cos ^{3} \theta}
$$

Once the cross sectional area of the struts was evaluated, the structure was brought to a form of only line elements and was analyzed by plane frame programs. The second moment of area of the struts was assigned zero values to simulate pin end actions of infill on the frame boundaries. By removing or assigning zero areas for the struts crossing the opening area, openings were accounted for. Some amount of judgment and approximation was necessary in formulating the struts around the openings. Strut formulation around a given opening is shown in Fig. (37). It was evident from the results that multiple strut models predict the first few natural frequencies reasonably. The limitation of the model was that the grid division to form the diagonal strut was not unique and it could not be easily done for the favorable positions of openings covered by full grids, also conforming to exact contact lengths and opening sizes was difficult. Equivalent frame model proposed by Liauw [25] was used to predict the free vibration response of infilled frames with central openings. The example frames of different aspect ratios were analyzed with central opening varying from 12 to 50 percent of the panel area. The first three natural frequencies and associated mode shapes were evaluated and compared with the corresponding finite element solutions. For zero opening case, the fundamental frequency was under estimated by about $12 \%$, but the error decreased as the opening sizes increased. In most cases, the mode shape prediction was generally in agreement with the finite element model for the predominant mode of vibration. The model was limited to only infill with central openings and also it could only be used for frames with non-separating infills.
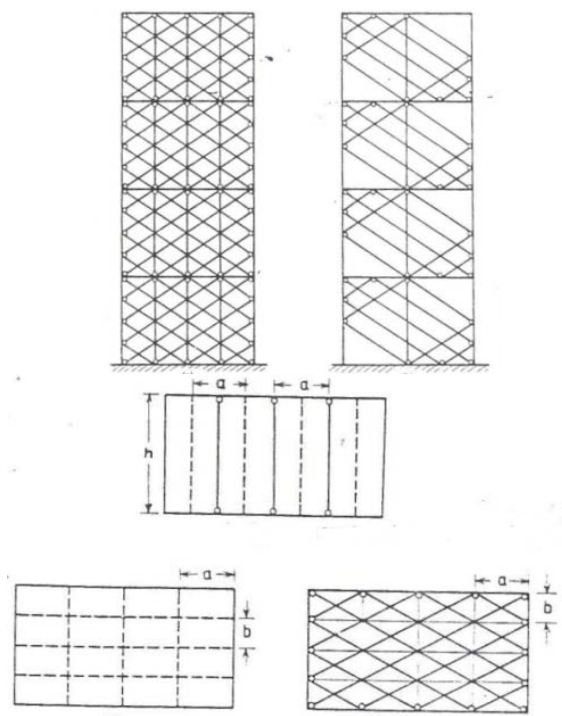

Fig. (36). Pin jointed diagonal and vertical struts and formation of vertical struts [34].
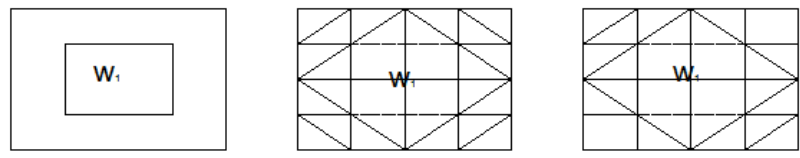

$\mathbf{\alpha}_{\mathrm{c}}=0.50$
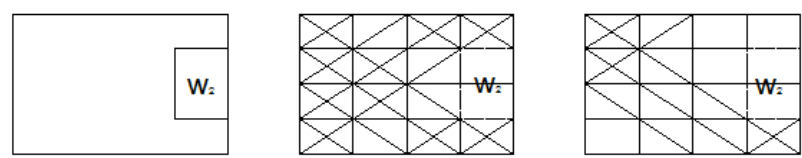

$\alpha_{c}=0.50$
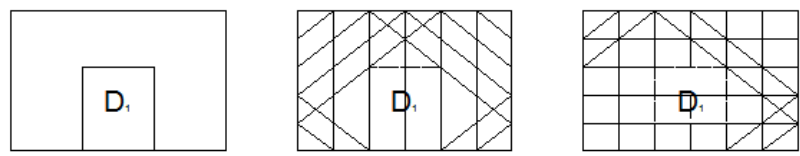

$\alpha_{c}=0.40$
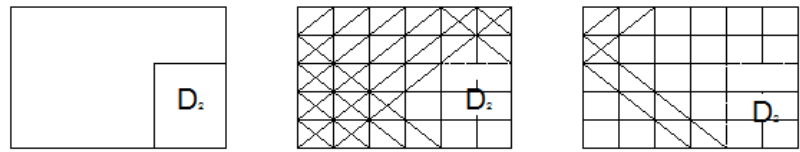

$\alpha_{\mathrm{c}}=0.40$

Fig. (37). Suggested strut formations around openings of various configurations [34].

Dynamic response and failure mechanism of a three story, two bay masonry infilled, non-ductile RC frames was 


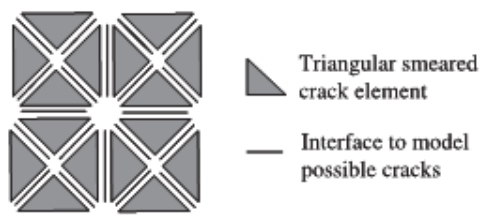

(a)

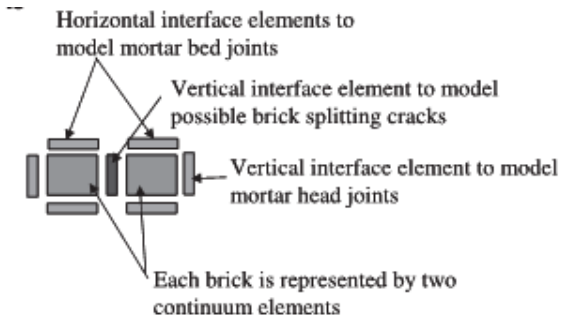

(b)

Fig. (38). Discretization scheme employed in finite element models: (a) reinforced concrete columns and (b) unreinforced masonry panels [35].

investigated by non-linear finite element analysis by Koutromanos et al. [35]. Authors used combination of discrete and smeared crack approach in the study. The finite element models were verified with results of quasi static and large scale shake table tests conducted on masonry infilled RC frames. Masonry-infilled RC frames had non-ductile reinforcement details representing existing structures constructed in the 1920s in California. Failure mechanism of these structural systems were complicated as it included one or more of the following: flexural and shear cracks in the frame members, diagonal and shear sliding cracks in the infill walls, frame-infill separation, and the compressive strut mechanism causing the crushing of the infill walls at loaded corners. Cohesive crack interface elements were used to capture dominant cracks in concrete members and brick units in a discrete fashion, as well as the behavior of masonry mortar joints. For modeling the compressive failure of concrete and brick, smeared-crack continuum elements were mainly used. To model dominant flexural and shear cracks in RC columns in a discrete fashion, interface elements were used between constant-strain triangular smeared-crack elements as shown in Fig. (38a). Dominant cracks in masonry infill panels were expected to run through mortar joints, with possible vertical splitting cracks sometimes developing in brick units. The discretization scheme shown in Fig. (38b)was employed to capture this behavior.

The reinforcing bars in concrete members were modeled with elasto-plastic truss elements such that majority of the nodes of the smeared-crack elements should be connected to at least one truss element; each reinforcing bar was split into several truss elements using the scheme shown in Fig. (39). The truss elements are so arranged that the right quantity of steel crosses each potential crack represented by interface elements. By introducing elasto-plastic springs joining the nodes of the horizontal interface elements crossed by the vertical bars, the dowel action of the vertical reinforcing bars was accounted for. The total cross-sectional area of the dowel springs at each section was assumed to be $25 \%$ of that of the vertical bars, while the yield stress of the springs was assumed to be $60 \%$ of that of the vertical steel. The constitutive models for the cohesive crack interface elements and smeared-crack elements used in the analyses was implemented in the finite element program FEAP. To account for mixed mode fracture, crack opening and closing, reversible shear dilatation, and interface compaction due to damage, the discrete cohesive crack model used to simulate the behavior of cracks in concrete, brick units, and mortar joints adopts a modified elasto-plastic formulation.

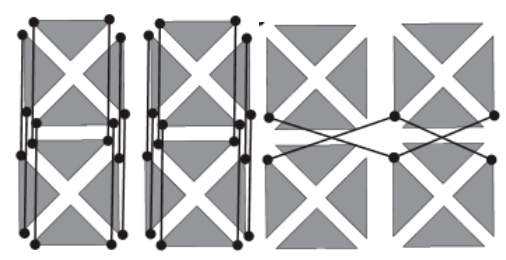

(a)

(b)

Fig. (39). Truss elements to model reinforcing bars in a column: (a) longitudinal bars and (b) transverse bars [35].

The constitutive models were used to simulate the response of masonry-infilled, non-ductile, RC frames tested at the University of Colorado, Boulder (CU) and the University of California, San Diego (UCSD). The test specimens correspond to portions of a $2 / 3$-scale model of a prototype building with design details representative of those used in the 1920 s in California. Two of the specimens (referred to as CU1 and CU2) were one story with one bay and were tested at $\mathrm{CU}$ with quasi-static cyclic loads and the third was three stories with two bays, and was tested on a shake table at UCSD. The test specimen with opening (CU2) and finite element model is shown in the Fig. (40a). The frames were infilled with two-wythe brick masonry walls; one had a solid wall and the other had a window opening. A constant vertical force of $312 \mathrm{kN}$ was applied on each specimen throughout test to simulate the effect of gravity loads. The specimens were subjected to a lateral displacement time history of gradually increasing amplitude, with two loading cycles for each displacement amplitude level. For CU2, the agreement between the analysis and test was found to be satisfactory in the positive direction, especially in the pre-peak regime Fig. (40a). The pre-peak response in the negative direction was not captured and peak strength was underestimated by $10 \%$.

From the cracking pattern of the structure shown in Fig. (41), diagonal/sliding cracks in the infill panels and shear cracks on the columns for both the actual specimen and the finite element model are evident. Though the cracking pattern in both the analysis and the test is a combination of diagonal/sliding cracks in the infill and shear cracks in the columns, one of the columns had a major shear crack developed close to the mid-height in the test, while in the finite element analysis, the shear crack occurred near the bottom of the column.Effect of the loading history on the inelastic frame response was investigated by monotonically increasing the lateral loads. It can be seen in Fig. (40b) that the loaddisplacement curves from the monotonic load analysis were similar to the envelope of the hysteresis curves from the cyclic load analyses. Influence of bottom-story walls was also studied. Though study included infilled frame with opening, 
effect of openings on failure mechanism and dynamic response of the frame were not presented.

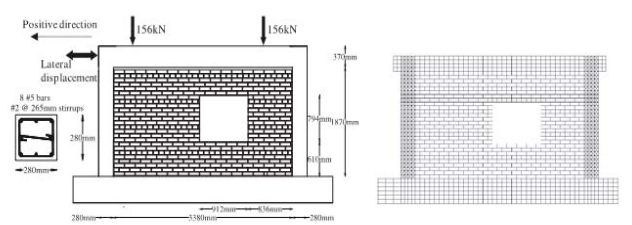

(a)

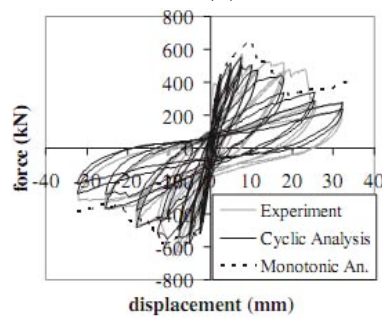

(b)

Fig. (40). (a) Masonry-infilled frame specimen subjected to quasistatic cyclic and finite element model (CU2), and (b) comparison of experimentally recorded and numerically obtained loaddisplacement curves for cyclically loaded masonry-infilled RC frame CU2 [35].
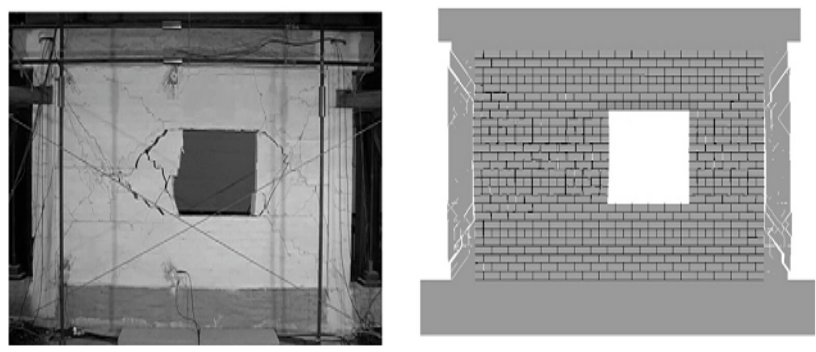

Fig. (41). Crack patterns observed from tests and analyses CU2 test and analysis [35]

Achyuta et al. [36] used finite element model to simulate the elastic behaviour of infilled frames with openings. Different material properties, complex nature of stress system existingat the interface of infill and frame,separation, slip and loss of friction at the interface were accommodated in finite element model. A simple iterative finite element method of analysis making use of the SAP IV computer program package was utilized for the analysis of infilled frames with openings. Analysis of infilled frames by taking into consideration all the factors at the interface of infill and frame (namely, separation, slip, and frictional loss at the contact surface) was proposed. Fig. (42a) represents finite element idealization of a typical infilled frame with opening. The bounding frame members were represented by prismatic beam elements having three degrees of freedom at each node and the continuum infill panel by two-dimensional fournoded rectangular plane stress elements having two degrees of freedom at each node. The interface between the frame and the infill was represented by short stiff beam elements having three degree of freedom at each node, but the node connecting the infill was made a structural hinge so that no moment is transferred from the link elements to the infill.

Wherever an opening had to be provided, for the corresponding elements in the infill panel very small values of thickness and modulus of elasticity and a high value of Pois- son's ratio were assigned, for example, $0.001 \mathrm{~cm}, 1.0 \mathrm{~kg} / \mathrm{cm}$, and 0.5 as compared to the actual values of $20.0 \mathrm{~cm}, 70,000$ $\mathrm{kg} / \mathrm{cm}$, and 0.15 , respectively. Thus a set of very thin virtual membrane elements having negligible thickness were generated. In the final output of results, stresses in the elements corresponding to the opening were very small. For all practical purposes they were taken as zero. This method of modeling created an underflow error, and a provision was made in the SAP IV program package itself to suppress the same. Separation, slip and frictional loss at the interface of frame and infill were allowed. Elastic behaviour of infilled frames with openings was studied considering the effects of relative stiffness of infill and frame, types of contact at the interface of infill and frame, types of opening, types of stiffeners around the opening, and the rigidity of stiffeners.

To study the effect of openings, central window opening and central door opening, limiting the height of the door to $2 / 3$ the height of infill panel, were taken into consideration in the analysis. Size of the window opening was varied from zero (solid infill) to $100 \%$ (open frame without any infill) and that of the door from zero to $66.67 \%$. The effect of size of window opening on the lateral stiffness of infilled frames is shown in Fig. (42b). It is evident that stiffness of the frames with separation is much lower compared to the ones with no separation. There is a sudden drop in stiffness of frames as the opening size increases, and the drop is drastic in the case of infills with no separation. It can be inferred that the contribution of the infill panel to the lateral stiffness is not considerable when compared to that of solid infilled frames, for cases of window opening area greater than $50 \%$ of the solid infilled area.

It was found from the finite element analysis that in case of infilled frames with full contact, the magnitudes of the maximum principal stresses at the corners of the opening and at the loaded corner of infill increase with the increase inthe size of the opening. When separation is allowed at the interface, compressive stress concentration increases further whereas the tensile stresses get relieved. To study whether stiffeners will improve the lateral stiffness of infilled frames with opening, window and door stiffeners were also considered Fig. (43).

Finite element analysis of frames with window/door opening strengthened by different types of stiffeners is carried out for a central window opening (area of opening $11.11 \%$ ) and a central door opening (area of opening $22.22 \%$ ). Rigidity of the stiffeners was also kept constant with a depth equal to $10.0 \mathrm{~cm}$ and width equal to $20.0 \mathrm{~cm}$. From the results it was seen that the stiffeners do not have significant effect in improving the lateral stiffness of infilled frames for the case when full contact exists at the interface of infill and bounding frame, but when separation takes place stiffeners do improve the lateral stiffness considerably. It was observed that, for the size of opening considered, stiffeners WS8 and DS6 increase lateral stiffness of the infilled frames with opening to such an extent that it is even greater than the corresponding value of solid infilled frame. To verify some of the theoretical results obtained in the analysis, experiments were conducted on 19 half scale reinforced concrete frames infilled with brick masonry with and without openings. Experiments were carried out in two phases: first 


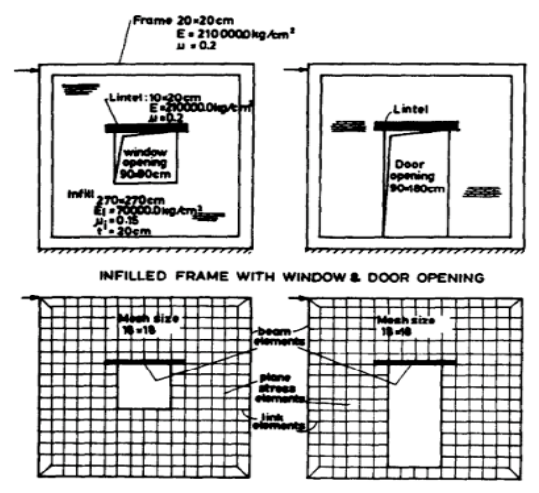

(a)

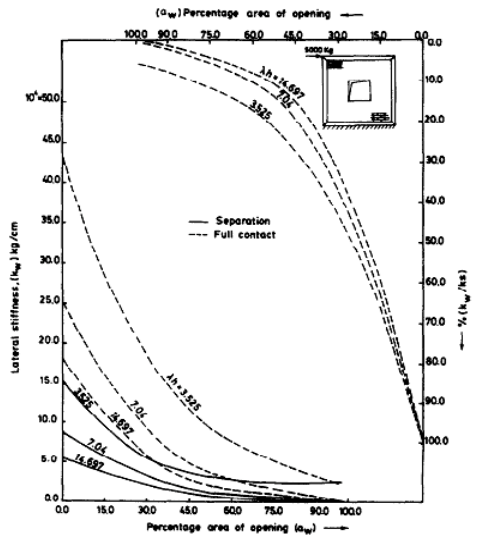

(b)

Fig. (42). (a) Finite element discretization, and (b) variation of lateral stiffness with the size of window opening [36].

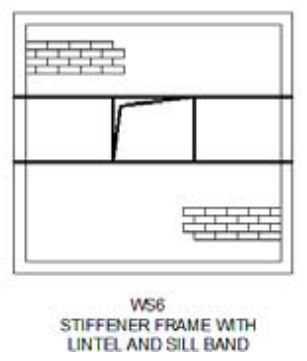

INTE AND SILL BAND

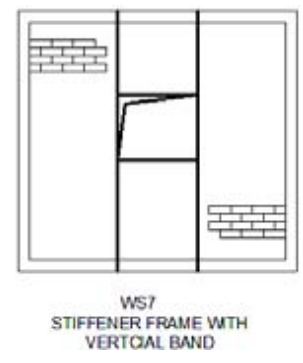

(a)
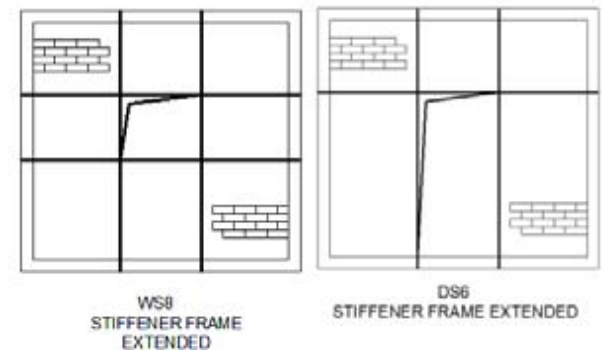

(b)

Fig. (43). (a) Types of window stiffeners, and (b) extended door stiffener [36].

phase consisted of 11 models to study the effect of the method of construction on the behaviour of infilled frames with and without openings, and second phase consisted of 8 models to study the effect of stiffeners on the elastic and ultimate behaviour of infilled frames with openings. Results of the experimental study were in good agreement with the numerical results. The nonlinearities involved in practical cases were not considered and the openings were restricted to only the centre of the infill.

\section{Infilled Frames with Openings and Seismic Codes}

Openings in infills are not looked upon in detail by most seismic codes [37]. Some codes use thumb rules for consideration of openings in masonry infills, for example, according to Eurocode8 [38], only the solid walls or walls with a single door or window opening are assumed to be imparting any significant strength to the structure. And, as per Nepal code [39] only those walls with an opening area less than $10 \%$ of the gross panel area are considered as resisting seismic loads. The seismic codes are also silent on analytical modeling of masonry infilled RC frame buildings with openings in masonry walls. Clearly, the seismic codes require revision to incorporate the analysis and design issues related to such buildings.

\section{SUMMARY AND CONCLUDING REMARKS}

Large number of experimental and analytical studies has been undertaken in the past by many researchers all over the world to investigate the effect of openings on the lateral stiffness, strength, failure modes, and other properties of infilled frames with openings. Past analytical studies mainly used finite element based techniques to study effect of openings on frames under lateral loads. The equivalent frame method and equivalent diagonal strut methods were used widely. Equations for estimating diagonal strut width were formulated based on these studies. Analytical techniques used are still in the process of evolution and still studies are going on in that respect because of the complexity of the problem. Different opening aspect ratios, positions and sizes were included to study the behaviour of infilled frames under the action of lateral loads. Past studies have concluded that masonry infills with openings also provide significant amount of stiffness to the frames. The lateral load carrying capacity of frames is also improved by infills with openings as compared to bare frames. It has been observed in both experimental and analytical studies that the failure modes of masonry infilled frames change drastically due to presence of openings in the walls. Other important properties, such as, deformability, ductility, and energy dissipation capacity are also dependent on size and location of openings in the infill walls. This shows the importance of considering the effects of openings in masonry walls of RC frames in analysis and design of buildings. Interestingly, this issue is not looked upon in detail by most seismic codes, some of which use simple thumb rules for consideration of openings in masonry infills. Therefore, revision of seismic codes is essential for careful analysis and design of such buildings.

The review of past studies suggests that though large number of experimental and analytical studies has been undertaken in the past, there are many gap areas in this field. Past research has been carried out in parts, and more importantly, addresses only the local concerns in that region. The 
effect of gravity load on the behaviour of infilled frames with openings has not been studied extensively.Also the effect of slab and its stiffening effects were also not considered in the past studies. Based on this, the analytical models are required to be improved to simulate the behaviour of infilled frames with openings. A collective effort is required from researchers working in this area to collate the information and data available on such buildings, and subsequently, to carry out a comprehensive testing of RC frames with masonry infills containing openings of various possible sizes and shapes and at various locations in the frame. Such a collective effort will be certainly able to develop a uniform method of analysis and design of such buildings, which are constructed almost everywhere.

\section{CONFLICT OF INTEREST}

The authors confirm that this article content has no conflicts of interest.

\section{ACKNOWLEDGEMENT}

First authors gratefully acknowledge the financial support received from the Ministry of Human Resource Development, Government of India during the course of post graduate programme.

\section{REFERENCES}

[1] S.V. Polyakov, Masonry in framed buildings: An investigation into the strength and stiffness of masonry infilling, Translation into English by G. L. Cairns. Gosdarstvenoeizdatel'stvoliteraturypostroitel'stvuiarkhitekture: Moscow 1956.

[2] H.A. Moghaddam, and P.J. Dowling, "The State of the Art in Infilled Frames", ESEE Research Report No. 87-2, Imperial College of Science and Technology, Civil Engineering Department: London, 1987.

[3] P.G. Asteris, S.T. Antoniou, D.S. Sophianopoulos, and C.Z. Chrysostomou, "Mathematical macromodeling of infilled frames: state of the art", J. Struct. Eng. ASCE, vol. 137, no. 12, pp. 15081517, 2011.

[4] D.V. Mallick, and R.P. Garg, "Effect of openings on the lateral stiffness of infilled frames", Proc. Inst. Civil Eng., UK, vol. 49, pp. 193-209, 1971.

[5] T.C. Liauw, "Tests on multi storey infilled frames subjected to dynamic lateral loading”, J. Am. Concrete Inst., Paper No. 76-26, pp. 551-563, 1979.

[6] D.J. Kakaletsis, and C. Karayannis, "Experimental investigation of infilled R/C frames with eccentric openings", Struct. Eng. Mech., vol. 26, no. 3, pp. 231-250, 2007.

[7] D.J. Kakaletsis, "Masonry infills with window openings and influence on reinforced concrete frame constructions", In: Seventh International Conference on Earthquake Resistant Engineering Structures, 11-13 May, Cyprus 2009

[8] A.A. Tasnimi, and A. Mohebkhah, "Investigation on the behavior of brick-infilled steel frames with openings, experimental and analytical approaches", Eng. Struct., vol. 33, pp. 968-980, 2011.

[9] ATC24, "Guidelines for Cyclic Seismic Testing of Components of Steel Structures", ATC24 report, Applied Technology Council: Redwood City, CA 1992.

[10] K.M. Mosalam, R.N. White, and P. Gergely, "Static response of infilled frames using quasi-static experimentation", J. Struct. Eng., ASCE, vol. 123, no. 11, pp. 228-237, 1997.

[11] J.L. Dawe, and C.K. Seah, "Behavior of masonry infilled steel frames", Can. J. Civil Eng., vol. 16, no. 6, pp. 865-876, 1989.

[12] S.P. Schneider, and S.J. Favieri, "Lateral strength of brick cladded steel frames", In: Eleventh World Conference on Earthquake Engineering, Acapulco, Mexico, paper No. 990, 1996.

[13] S.P. Schneider, B.R. Zagers, and D.P. Abrams, "Lateral strength of steel frames with masonry infills having large opening", J. Struct. Eng., ASCE, vol. 124, no. 8, pp. 896-904, 1998.
[14] K.C. Voon, and J.M. Ingham, "Experimental in-plane strength investigation of reinforced concrete masonry walls with openings", J. Struct. Eng. ASCE, vol. 134, no. 5, pp. 758-768, 2008.

[15] NZS4229, New Zealand Standard concrete masonry buildings not requiring specific design, Standards New Zealand, New Zealand, 1999.

[16] Y.J. Chiou, J.C. Tzeng, and Y.W. Liou, "Experimental and analytical study of masonry infilled frames", J. Struct. Eng. ASCE, vol. 125, no. 10, pp. 1109-1117, 2006.

[17] S. Satyanarayanan, and P. Govindan, "Experimental behaviour of infilled frame under static loading", Indian Concrete J., vol. 63, pp. 542-552, 1989

[18] T.C. Liauw, and K.H. Kwan, "Plastic theory of non-integral infilled frames", Proc. Inst. Civil Eng., UK, vol. 75, no. 2, pp. 379-396, 1983.

[19] M. Mohammadi, V. Akrami, and R.M. Ghazi, "Methods to improve infilled frame ductility", J. Struct. Eng. ASCE, vol. 137, no. 6, pp. 646-653, 2011.

[20] A. Colombo, P. Negro, and G. Verzeletti, "Improving ductility and energy-dissipation capacity of infills by means of polymeric nets", In: Proceedings of the Twelfth World Conference on Earthquake Engineering, Auckland, New Zealand, January 30 - February 4 , 2000.

[21] S.G. Buonopane, and R.N. White, "Pseudodynamic testing of masonry infilled reinforced concrete frame", J. Struct. Eng. ASCE, vol. 125 , no. 6 , pp. 578-589, 1999.

[22] B. Stafford-Smith, "Lateral stiffness of infilled frames", J. Struct. Div. ASCE, vol. 88, no. ST6, pp. 183-199, 1962.

[23] P.G. Asteris, "Lateral stiffness of brick masonry infilled plane frames", J. Struct. Eng. ASCE, vol. 129, no. 8, pp. 1071-1079, 2003.

[24] M. Papia, "Analysis of infilled frames using a coupled finite element and boundary element solution scheme", Int. J. Numer. Methods Eng., vol. 26, no. 3, pp. 731-742, 1998.

[25] T.C. Liauw, "An approximate method of analysis for infilled frames with or without opening", Build. Sci., vol. 7, pp. 233-238, 1972.

[26] T.C. Liauw, and S.W. Lee, "On the behaviour and the analysis of multistory infilled frames subject to lateral loading", Proc. Inst. Civil Eng., UK, vol. 63, part 2, pp. 641-656, 1977.

[27] A. Mohebkhah, A.A. Tasnimi, and H.A. Moghadam, "A modified three-strut (MTS) model for masonry-infilled steel frames with openings", J. Seismol. Earthquake Eng., vol. 9, no. 1 \& 2, pp. 3948, 2007.

[28] W.W. El-Dakhakhni, M. Elgaaly, and A.A. Hamid, "Three-strut model for concrete masonry-infilled steel frames", J. Struct. Eng. ASCE, vol. 129, no. 2, pp. 177-185, 2003.

[29] A. Mohebkhah, A. A. Tasnimi, and H.A. Moghadam, "Nonlinear analysis of masonry-infilled steel frames with openings using discrete element method", J. Constr. Steel Res., vol. 64, pp. 1463 $1472,2008$.

[30] G. Mondal, and S.K. Jain, "Lateral stiffness of masonry infilled reinforced concrete (RC) frames with central opening", Earthquake Spectra, vol. 24, no. 3, pp. 701-723, 2008.

[31] R.G. Drysdale, A.A. Hamid, and L.R. Baker, Masonry Structures. Behaviour And Design, Prentice-Hall: New Jersey, USA, 1994.

[32] E. Smyrou, C. Blandon, S. Antoniou, R. Pinho, and F.G. Crisafulli, "Implementation and verification of a masonry panel model for nonlinear dynamic analysis of infilled RC frames", Bull. Earthquake Eng., vol. 9, pp. 1519-1534, 2011.

[33] F.G. Crisafulli, "Seismic Behaviour of Reinforced Concrete Structures with Masonry Infills", Ph.D. Thesis, University of Canterbury, Christchurch, New Zealand 1997.

[34] V. Thiruvengadam, "On the natural frequencies of infilled frames", Earthquake Eng. Struct. Dyn., vol. 13, pp. 401-419, 1985.

[35] I. Koutromanos, A. Stavridis, P.B. Shing, and K. Willam, "Numerical modeling of masonry-infilled RC frames subjected to seismic loads", Comput. Struct., vol. 89, pp. 1026-1037, 2011.

[36] H. Achyutha, R. Jagadish, P.S. Rao, and S.S. Rahman, "Finite element simulation of the elastic behaviour of infilled frames with openings", Comput. Struct., vol. 23, no. 5, pp. 685-696, 1986.

[37] H.B. Kaushik, D.C. Rai, and S.K. Jain, "Code approaches to seismic design of masonry-infilled reinforced concreteframes: a stateof-the-art review", Earthquake Spectra, vol. 22, no. 4, pp. 961-983, 2006. 
[38] Eurocode8, Design of structures for earthquake resistance - Part 1: General rules, seismic actions and rules for buildings, prEN 1998-

1, European Committee of Standardization, Brussels 2003.
[39] NBC201, Nepal national building code for mandatory rules of thumb for reinforced concrete buildings with masonry infill, Ministry of Housing and Physical Planning, Department of Buildings: Nepal 1995.

Received: December 17, 2011

Revised: June 04, 2012

Accepted: June 05, 2012

(C) Surendran and Kaushik; Licensee Bentham Open.

This is an open access article licensed under the terms of the Creative Commons Attribution Non-Commercial License (http://creativecommons.org/licenses/by-nc/3.0/) which permits unrestricted, non-commercial use, distribution and reproduction in any medium, provided the work is properly cited. 